NASA/TM-2009-215507

Frozen Chemistry Effects on Nozzle Performance Simulations

Dennis A. Yoder and Nicholas J. Georgiadis

Glenn Research Center, Cleveland, Ohio

Michael R. O'Gara

Embry Riddle Aeronautical University, Daytona Beach, Florida 


\section{NASA STI Program . . . in Profile}

Since its founding, NASA has been dedicated to the advancement of aeronautics and space science. The NASA Scientific and Technical Information (STI) program plays a key part in helping NASA maintain this important role.

The NASA STI Program operates under the auspices of the Agency Chief Information Officer. It collects, organizes, provides for archiving, and disseminates NASA's STI. The NASA STI program provides access to the NASA Aeronautics and Space Database and its public interface, the NASA Technical Reports Server, thus providing one of the largest collections of aeronautical and space science STI in the world. Results are published in both non-NASA channels and by NASA in the NASA STI Report Series, which includes the following report types:

- TECHNICAL PUBLICATION. Reports of completed research or a major significant phase of research that present the results of NASA programs and include extensive data or theoretical analysis. Includes compilations of significant scientific and technical data and information deemed to be of continuing reference value. NASA counterpart of peer-reviewed formal professional papers but has less stringent limitations on manuscript length and extent of graphic presentations.

- TECHNICAL MEMORANDUM. Scientific and technical findings that are preliminary or of specialized interest, e.g., quick release reports, working papers, and bibliographies that contain minimal annotation. Does not contain extensive analysis.

- CONTRACTOR REPORT. Scientific and technical findings by NASA-sponsored contractors and grantees.

- CONFERENCE PUBLICATION. Collected papers from scientific and technical conferences, symposia, seminars, or other meetings sponsored or cosponsored by NASA.

- SPECIAL PUBLICATION. Scientific, technical, or historical information from NASA programs, projects, and missions, often concerned with subjects having substantial public interest.

- TECHNICAL TRANSLATION. Englishlanguage translations of foreign scientific and technical material pertinent to NASA's mission.

Specialized services also include creating custom thesauri, building customized databases, organizing and publishing research results.

For more information about the NASA STI program, see the following:

- Access the NASA STI program home page at http://www.sti.nasa.gov

- E-mail your question via the Internet to help@ sti.nasa.gov

- Fax your question to the NASA STI Help Desk at 301-621-0134

- Telephone the NASA STI Help Desk at 301-621-0390

- Write to: NASA Center for AeroSpace Information (CASI) 7115 Standard Drive Hanover, MD 21076-1320 
NASA/TM-2009-215507

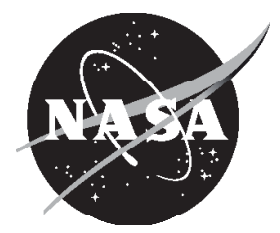

\section{Frozen Chemistry Effects on Nozzle Performance Simulations}

Dennis A. Yoder and Nicholas J. Georgiadis

Glenn Research Center, Cleveland, Ohio

Michael R. O'Gara

Embry Riddle Aeronautical University, Daytona Beach, Florida

Prepared for the

38th Fluid Dynamics Conference and Exhibit

sponsored by the American Institute of Aeronautics and Astronautics

Seattle, Washington, June 23-26, 2008

National Aeronautics and

Space Administration

Glenn Research Center

Cleveland, Ohio 44135 


\section{Acknowledgments}

The authors would like to thank the Department of Defense Test Resource Management Center (TRMC) Test and Evaluation/ Science and Technology (T\&E/S\&T) Program for their support. This work was jointly funded by the NASA Fundamental Aeronautics Hypersonics Project and by the T\&E/S\&T Program through the High Speed/Hypersonic Test focus area managed from Arnold Engineering Development Center, Arnold Air Force Base, Tennessee.

Level of Review: This material has been technically reviewed by technical management.

Available from

NASA Center for Aerospace Information 7115 Standard Drive

Hanover, MD 21076-1320
National Technical Information Service 5285 Port Royal Road Springfield, VA 22161

Available electronically at http://gltrs.grc.nasa.gov 


\title{
Frozen Chemistry Effects on Nozzle Performance Simulations
}

\author{
Dennis A. Yoder and Nicholas J. Georgiadis \\ National Aeronautics and Space Administration \\ Glenn Research Center \\ Cleveland, Ohio 44135 \\ Michael R. O'Gara \\ Embry Riddle Aeronautical University \\ Daytona Beach, Florida 32114
}

\begin{abstract}
Simulations of exhaust nozzle flows are typically conducted assuming the gas is calorically perfect, and typically modeled as air. However the gas inside a real nozzle is generally composed of combustion products whose thermodynamic properties may differ. In this study, the effect of gas model assumption on exhaust nozzle simulations is examined. The three methods considered model the nozzle exhaust gas as calorically perfect air, a calorically perfect exhaust gas mixture, and a frozen exhaust gas mixture. In the latter case the individual non-reacting species are tracked and modeled as a gas which is only thermally perfect. Performance parameters such as mass flow rate, gross thrust, and thrust coefficient are compared as are mean flow and turbulence profiles in the jet plume region. Nozzles which operate at low temperatures or have low subsonic exit Mach numbers experience relatively minor temperature variations inside the nozzle, and may be modeled as a calorically perfect gas. In those which operate at the opposite extreme conditions, variations in the thermodynamic properties can lead to different expansion behavior within the nozzle. Modeling these cases as a perfect exhaust gas flow rather than air captures much of the flow features of the frozen chemistry simulations. Use of the exhaust gas reduces the nozzle mass flow rate, but has little effect on the gross thrust. When reporting nozzle thrust coefficient results, however, it is important to use the appropriate gas model assumptions to compute the ideal exit velocity. Otherwise the values obtained may be an overly optimistic estimate of nozzle performance.
\end{abstract}

\section{Nomenclature}

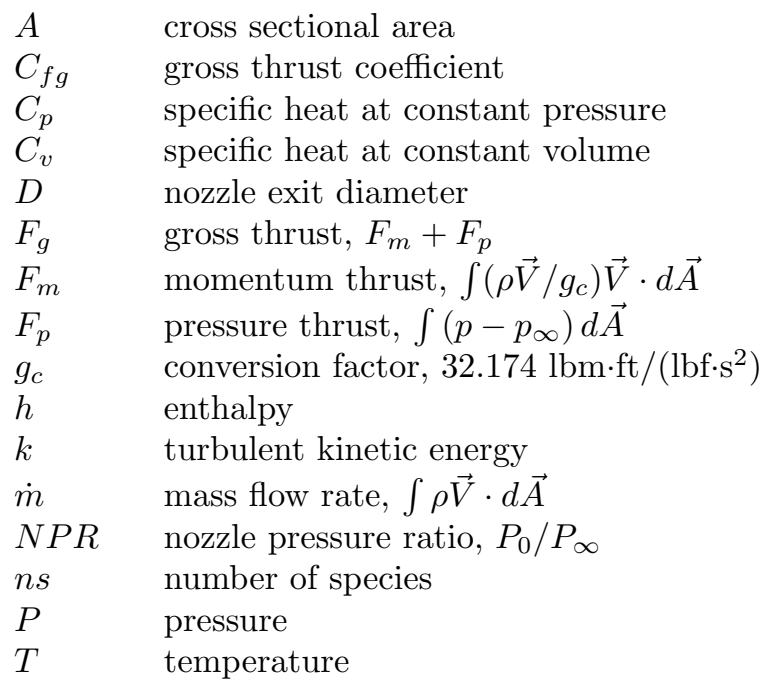




$\begin{array}{ll}R & \text { gas constant } \\ r & \text { radial position } \\ s & \text { entropy } \\ u_{\tau} & \text { friction velocity, } \sqrt{\tau_{w} / \rho_{w}} \\ U & \text { axial velocity } \\ V & \text { velocity } \\ V_{i d e a l} & \text { nozzle ideal exit velocity } \\ x & \text { axial distance from nozzle exit plane } \\ Y & \text { species mass fraction } \\ \Delta y & \text { distance to the nearest wall } \\ y^{+} & \text {nondimensional near-wall spacing, } \Delta y \cdot u_{\tau} / \nu \\ \nu & \text { kinematic viscosity } \\ \rho & \text { density } \\ \gamma & \text { ratio of specific heats, } C_{p} / C_{v} \\ \tau & \text { shear stress } \\ & \\ \text { subscripts } / \text { superscripts } \\ e & \text { nozzle exit } \\ 0 & \text { stagnation condition } \\ w & \text { wall } \\ * & \text { throat } \\ \infty & \text { freestream }\end{array}$

\section{Introduction}

Computational fluid dynamics (CFD) continues to become a more integral part of the design process. Advances in computational hardware have resulted in faster turn-around times for a given simulation, and now allow researchers to consider more complex problems involving a larger parametric space, larger domain sizes, and/or more advanced physical modeling.

At NASA Glenn in the area of propulsion, and particularly in the area of exhaust nozzle flows, CFD is currently used to (1) examine the performance characteristics of a given nozzle design and identify loss mechanisms, and (2) generate nozzle plume simulations which provide noise source estimates for acoustic analogy methodologies such as that described in reference 1. Some examples of these types of nozzle assessments are given in references $2-5$. The first examines the flowfield inside a lobed mixer-ejector nozzle in order to better understand sidewall effects on the mixedness of the exhaust gas. References 3 and 4 investigate the performance penalty of placing wedge or vane flow diverters into the internal fan stream of a dual-stream turbofan engine in order to reduce the perceived jet noise. The last provides an overview of the current state of jet noise prediction capabilities, which rely upon CFD to provide the mean flow and turbulence quantities in the jet plume region.

Simulations such as these have traditionally been conducted assuming that the exhaust behaves as a calorically perfect gas, usually air. This is done to match experiments using unheated air, and it simplifies the simulation since the specific heats are treated as constants. However, these perfect gas simulations often allow only one working fluid, thus requiring that the same thermodynamic properties be used for both the internal and external regions of the flow. In addition, the gas within a real nozzle contains additional species which result from the combustion process and may alter the thermodynamic properties of the gas. The expansion of the gas through the nozzle also results in a change in static temperature of the flow. Using the isentropic relations for perfect gas air as a guide, one can estimate the static temperature variation as a function of Mach number. As shown in figure 1 the steepest portion of this curve occurs at low supersonic speeds. At a nozzle exit Mach number of 1.0, the temperature is $83 \%$ of the stagnation value. However, at an exit Mach number of 2.0, the temperature is only $55 \%$. If the gas is not calorically perfect, the thermodynamic properties will vary with the temperature inside the nozzle. As figure 2 illustrates, both air and exhaust gas experience the most significant reduction in $\gamma$ between temperatures of $1000-2000{ }^{\circ} \mathrm{R}$. Therefore one would expect hot supersonic jets might benefit from more realistic modeling of the exhaust gas.

In modeling chemically reacting flows, the mass fractions of the individual chemical species are tracked 
and the mixture properties at any point in the flowfield depend upon the mixture composition and the thermodynamic properties of the individual species. These thermodynamic properties are in turn functions of the local temperature, which makes the gas thermally perfect. Computing the reaction rate source terms can be computationally expensive and reduce the allowable timestep. For gas turbine engines, where the flow entering the nozzle has passed through the turbine and the combustion process is essentially complete, one can make the simplifying assumption that the reaction rates are zero. Under this frozen chemistry assumption, diffusion is the only mechanism for changing the species concentrations.

This paper investigates the effect of the gas model assumptions on nozzle exhaust simulations by comparing the results of three modeling approaches: (1) the nozzle flow is treated as air and assumed to be a calorically perfect gas, (2) the flow is treated as a calorically perfect gas representative of the combustion products, and (3) the combustion products are modeled using frozen chemistry. The comparisons include predicted performance parameters such as mass flow rates and thrust, as well as mean flow and turbulence values within the jet plume region which may affect jet noise predictions.

In addition, simulations are carried out using two different near-wall turbulence treatments. The first type is referred to as wall integration or low (turbulence) Reynolds number models. This technique incorporates near wall source terms into the turbulence transport equations so that one can integrate the equations down to and including the laminar sublayer region $\left(y^{+} \leq 5\right)$. In order to properly capture the near wall boundary layer the first grid point off the wall should be located well within the sublayer, generally near $y^{+}=1$. The second type of near wall model is referred to as the wall function technique. This method assumes that the velocity profile obeys the law of the wall, and the near wall flow is prescribed through boundary conditions rather than resolved. The method requires that the first point off the wall lie within the log-layer region, typically found between $y^{+}$values of 30 and approximately 150 . Because of the assumptions inherent in the wall function development, that class of near-wall treatment is less broadly applicable than wall integration models. However, the less stringent near-wall grid requirement can reduce the number of computational grid points needed and also increase the local timestep for a given CFL number.

\section{Experimental Configurations}

The first set of simulations were computed for an axisymmetric convergent nozzle. The specific nozzle used was the 2.0 inch diameter acoustic reference nozzle (ARN) from reference 6 . The computational results will be compared with experimental data from setpoint 23 , which had a jet supply stream heated such that the static temperature at the nozzle exit plane was 1.76 times the ambient static temperature and operated at a nozzle pressure ratio (NPR) of 1.103. Measurements of velocity and turbulent kinetic energy are available from particle image velocimetry (PIV). The data include centerline measurements along with profile measurements at various axial locations downstream of the nozzle exit.

The second set of simulations were computed for a supersonic nozzle that was tested at the NASA Langley Research Center (LaRC) Jet Noise Laboratory. ${ }^{7}$ The nozzle has an exit diameter of 3.6 inches and was operated near fully expanded conditions to Mach 2. Several different datasets are available for various nozzle total temperatures. The particular dataset used in this study had a total temperature of $2460{ }^{\circ} \mathrm{R}$. Centerline measurements of static temperature and pressure, total pressure and axial velocity were taken.

\section{Analytical Modeling}

Using a simple one-dimensional analysis of an inviscid calorically perfect gas, one can show that for a shock-free nozzle the mass flow rate and nozzle exit velocity are given by:

$$
\begin{gathered}
\dot{m}=\sqrt{\frac{2 \gamma}{\gamma-1} \frac{1}{R T_{0}}\left[\left(\frac{P_{0}}{P_{e}}\right)^{(\gamma-1) / \gamma}-1\right]\left(\frac{P_{0}}{P_{e}}\right)^{(\gamma-1) / \gamma}} P_{e} A_{e} g_{c} \\
V_{e}=\sqrt{\frac{2 \gamma}{\gamma-1} R T_{0}\left[1-\left(\frac{P_{0}}{P_{e}}\right)^{(1-\gamma) / \gamma}\right]}
\end{gathered}
$$


The thrust due to the momentum of the flow exiting the nozzle is,

$$
F_{m}=\frac{2 \gamma}{\gamma-1}\left[\left(\frac{P_{0}}{P_{e}}\right)^{(\gamma-1) / \gamma}-1\right] P_{e} A_{e}
$$

and the pressure thrust due to imperfect expansion inside the nozzle is:

$$
F_{p}=\left(1-\frac{P_{\infty}}{P_{e}}\right) P_{e} A_{e}
$$

The sum of these is the gross thrust.

$$
F_{g}=\left\{\frac{2 \gamma}{\gamma-1}\left[\left(\frac{P_{0}}{P_{e}}\right)^{(\gamma-1) / \gamma}-1\right]+\left(1-\frac{P_{\infty}}{P_{e}}\right)\right\} P_{e} A_{e}
$$

For a convergent nozzle, the flow either expands to the freestream pressure or becomes choked at the nozzle exit. The exit pressure can therefore be determined from:

$$
\frac{P_{e}}{P_{\infty}}=\max \left[1 ; \frac{P_{0}}{P_{\infty}}\left(1+\frac{\gamma-1}{2}\right)^{-\gamma /(\gamma-1)}\right]
$$

For a choked convergent-divergent nozzle, the exit pressure can be determined from the exit Mach number which must satisfy the area ratio relation.

$$
\begin{gathered}
\frac{A_{e}}{A^{*}}=\frac{1}{M_{e}}\left(\frac{\frac{\gamma+1}{2}}{1+\frac{\gamma+1}{2} M_{e}^{2}}\right)^{\frac{-(\gamma+1)}{2(\gamma-1)}} \\
\frac{P_{e}}{P_{\infty}}=\frac{P_{0}}{P_{\infty}}\left(1+\frac{\gamma-1}{2} M_{e}^{2}\right)^{-\gamma /(\gamma-1)}
\end{gathered}
$$

Shock losses within the nozzle complicate the analysis. Fortunately, for the near fully expanded conditions of the present C-D nozzle, the above relations are sufficient.

An important thing to note from this analysis is that both the mass flow rate and exit velocity are directly dependent upon the gas constant and the operating stagnation temperature of the nozzle. The thrust is independent of the gas constant and is only indirectly influenced by temperature through $\gamma$.

\section{Numerical Setup}

The simulations were performed using the latest release of Wind-US, version 2.0. This CFD code is developed by the NPARC Alliance, a partnership between the NASA Glenn Research Center (GRC) and the Air Force's Arnold Engineering Development Center (AEDC), along with significant contributions from The Boeing Company. Wind-US is a general purpose Navier-Stokes flow solver capable of simulating a multitude of fluid flow physics and is well suited for high speed flows.

Both nozzle geometries have been extensively investigated using previous versions of Wind. ${ }^{8-10}$ Those studies have largely focused on the effects of turbulence models on the decay of jet plumes where the exhaust gas was modeled using air and treated as calorically perfect. For the current series of calculations, Menter's Shear Stress Transport (SST) turbulence model ${ }^{11}$ was used with $\operatorname{Pr}_{t}=0.70$ and three different gas models. The first used air as the working fluid and was assumed to be calorically perfect. The second assumed that the exhaust gas mixture is calorically perfect and comprised of the following species mass fractions: nitrogen (N2) 78.066\%, oxygen (O2) 15.613\%, carbon dioxide (CO2) 3.528\%, and water vapor (H2Og) 2.793\%. The third series of calculations modeled this exhaust gas mixture using the specified species mass fractions and frozen chemistry, which is to say that the chemical kinetics were not enabled and the gas was treated as thermally perfect. These three gas models will be referred to as perfect gas air, perfect gas exhaust and frozen gas exhaust. 
For the frozen chemistry calculations, the freestream species mass fractions were set at $0.79 \% \mathrm{~N} 2$ and $0.21 \%$ O2. Other lesser species, such as Argon, were ignored. For the perfect gas simulations Wind-US only allows one working fluid, so both the nozzle and freestream flow were modeled using the same gas properties. Effective values of the ratio of specific heats for the perfect gas exhaust cases are based upon those of the frozen gas exhaust evaluated at the nozzle stagnation temperature (ie, $\gamma=\gamma\left(T_{0}\right)$ ). Note that these values differ between the two nozzle cases because of differences in the operating stagnation temperatures.

All of the simulations were modeled using a multi-block structured grid approach: one zone for the internal flow, another for the freestream surrounding the nozzle, and a third downstream zone for the plume region. Wall integration grids for both nozzles were available from previous studies. These grids were modified for use with wall functions by redistributing the near wall points. The targeted placement of the first point off the wall was $y^{+}$between 30 and 50, but determining this location a priori is complicated by the fact that $y^{+}$depends upon the local flow. Since the wall integration solutions were available, they were used to help determine the physical near-wall spacing needed to achieve the desired $y^{+}$.

Inside the nozzle, stagnation values for both pressure and temperature were specified. Freestream values were specified for the external flow. Heat transfer effects were not considered as part of this study and all of the viscous walls were modeled as adiabatic.

\section{Post-Processing}

Assumptions regarding the type of gas model also have implications on the calculation of the nozzle performance metrics. A common nozzle performance parameter is the gross thrust coefficient, defined in terms of the gross thrust, the actual nozzle mass flow rate, and a nozzle ideal exit velocity.

$$
C_{f g}=F_{g} g_{c} / \dot{m} V_{\text {ideal }}
$$

The gas model assumption directly effects the calculation of the ideal exit velocity, which is the theoretical velocity obtained by a perfectly expanded isentropic process. An assumption is usually made that the gas is calorically perfect which implies that the specific heats are constant and allows one to write a closed-form expression for $V_{\text {ideal }}$. In many instances values for air are used in this calculation. However, a more accurate result takes the temperature dependence of the specific heats into consideration. Details of calculating the ideal velocity are given in Appendix A for both thermally perfect and calorically perfect gases.

The present thrust coefficient results have been calculated using three different values for the ideal velocity which mirror the assumptions used in the simulations. The first assumes that the nozzle flow is air and is calorically perfect. The second assumes the nozzle flow is a gaseous mixture representative of the combustion products, but remains calorically perfect. The third also accounts for the presence of combustion products, which are only thermally perfect.

\section{Subsonic Nozzle}

The mesh utilized for the subsonic nozzle case is shown in figure 3. The domain extends 40 diameters downstream and 25 diameters in the radial direction. In a previous study ${ }^{9}$ involving Wind, grid independence was demonstrated through grid sequencing. Thus a new grid independence study was not undertaken. In order to compare the turbulent wall integration and wall function approaches, additional simulations were conducted using a grid which was more loosely clustered to the viscous wall regions. Figures 4 and 5 illustrate the differences in near-wall resolution of the wall integration and wall function grids.

For this case the freestream conditions were set to $M_{\infty}=0.01, P_{\infty}=14.3 \mathrm{psi}$, and $T_{\infty}=530{ }^{\circ} \mathrm{R}$, while the nozzle stagnation conditions were $P_{0}=15.770 \mathrm{psi}$ and $T_{0}=962{ }^{\circ} \mathrm{R}$. Evaluating the exhaust gas thermodynamic properties at this stagnation temperature yielded a value of $\gamma=1.373$, which was used for the perfect gas exhaust simulation. Table 1 summarizes the gas model constants used in the various simulations of this case.

The temperature within this subsonic nozzle was relatively low and, as shown in figure 6 , was found to vary only $3 \%$ through the nozzle. As a result, the thermodynamic properties of the gas for the frozen chemistry case are nearly constant within the nozzle ( $\gamma$ increased only $0.10 \%$ from its inflow value of 1.373$)$. In the plume region, however, $\gamma$ experienced a greater increase as the exhaust gas species mixed with the freestream air. This is shown in figure 7 .

The variation of $\gamma$ within the plume region has little effect on the centerline values of mean axial velocity 
and turbulent kinetic energy shown in figures 8 and 9. Radial profiles of $u$ and $k$ in figures 10 and 11 also reveal no significant differences between the three gas model results. In addition, the wall function results are in excellent agreement with those using wall integration. Based upon the similarity in these solutions one would expect noise predictions based upon them to be nearly identical.

Table 2 summarizes the mass flow rate and thrust values predicted by the various models. For this nozzle, the simple one-dimensional inviscid analysis predicts that the exhaust gas will have approximately $1 \%$ less mass flow rate compared to perfect gas air, but the difference in $\gamma$ will have a negligible effect on the gross thrust. The CFD results shown in the table confirm these trends. The use of wall functions consistently results in approximately $1 \%$ less mass flow rate and gross thrust compare to the wall integration results. A closer examination of the wall function solutions reveals that the resultant near-wall grid spacing near the nozzle exit grows to roughly $y^{+}=50$. While still acceptable for the wall function procedure, this spacing yields only about 6 points inside the boundary layer. It should be noted that identifying the boundary layer edge is complicated by the fact that the flow inside the nozzle is two dimensional. An additional series of simulations was conducted using a revised wall function grid which had a near-wall grid spacing near the nozzle exit of $y^{+} \approx 20$. Compared with the wall integration results, the difference in mass flow rate on the revised grid is reduced to approximately $0.25 \%$ and the difference in thrust is reduced to less than $0.4 \%$.

The gross thrust coefficient results given in Table 3 have been computed using three different gas model assumptions in the calculation of $V_{\text {ideal }}$. The first column of results has been computed using the nozzle ideal exit velocity for perfect gas air. As is evident, normalizing the exhaust gas flows in this manner exaggerates the nozzle efficiency. In the second column of results, the ideal velocity is computed using values for $R$ and a constant effective $\gamma$ which more closely models the actual exhaust gas. Using this technique, the ideal velocity for the exhaust gas is approximately $1 \%$ larger than for perfect gas air. With this adjustment, the thrust coefficient results are observed to be in very close agreement with the simulation results for perfect gas air. The third column of results have been normalized by a $V_{\text {ideal }}$ value that is based upon the mixture gas constant and a variable $\gamma$. Due to the limited variation in temperature and $\gamma$ within the nozzle, the value of $V_{\text {ideal }}$ computed using this thermally perfect procedure differs very little from that computed using an effective perfect gas. The change in the frozen gas thrust coefficient results is only $0.1 \%$.

For this convergent nozzle operating at a relatively low temperature, the choice of gas model effects the predicted mass flow rate by roughly one percent and differences in gross thrust are negligible. Both of these trends match those provided by the analytical model. When computing the nozzle ideal exit velocity for use in the gross thrust coefficient, the use of a perfect gas assumption appears to be satisfactory, provided one uses thermodynamic properties of the actual gas rather than air. Because there is little temperature variation within this nozzle, there is little advantage to using the thermally perfect procedure for computing $V_{\text {ideal }}$.

\section{Supersonic Nozzle}

The mesh for the supersonic nozzle shown in figure 12 is similar to that used in previous jet plume studies ${ }^{9,10}$ but has undergone some refinement inside the nozzle to improve thrust predictions. A series of axial and radial grid refinement studies revealed that additional streamwise resolution was needed within the convergent section of the nozzle in order to improve predictions of the initial flow acceleration and mass flow conservation within the nozzle. Figures 13 and 14 compare the near-wall spacing for the wall integration and wall function grids. Because the lip of the supersonic nozzle is considerably thinner than that of the subsonic nozzle, the wall function grid for this case provides significantly less radial resolution of the initial shear layer region.

The freestream conditions were set to $M_{\infty}=0.20, P_{\infty}=14.7 \mathrm{psi}$, and $T_{\infty}=530{ }^{\circ} \mathrm{R}$. Inside the nozzle stagnation conditions were set to $P_{0}=115 \mathrm{psi}$ and $T_{0}=2460{ }^{\circ} \mathrm{R}$. At this elevated stagnation temperature, the value of $\gamma$ for the exhaust gas was found to be 1.305 , which is about $7 \%$ less than the typical value used for air and about $5 \%$ less than the value used for the subsonic nozzle exhaust gas. Table 4 summarizes the thermodynamic properties for each of the gas models used for this series of simulations.

Because of the higher operating temperature and greater expansion within this nozzle, it is a better test case for illustrating the effect that the perfect gas and frozen chemistry models have on the predicted nozzle performance. Figure 15 compares the static temperature variation along the nozzle centerline. This case exhibits a $40 \%$ change in temperature through the nozzle and differences between the perfect gas air and perfect gas exhaust are clearly evident. The perfect gas air results are noticeably overexpanded relative to 
the experimental data. The perfect and frozen gas exhaust models are in much better agreement, with the frozen gas exhaust results most closely matching the nozzle exit temperature data and providing a minor improvement within the jet decay region.

Figure 16 compares contours of the static temperature predicted with the various gas models. Differences in how the models compute thermodynamic properties result in a slightly different expansion through the nozzle and within the plume region. This is more easily seen by examining the Mach number contours in the jet potential core region, figure 17. The perfect gas air simulation expands quickest through the nozzle, though the effects of this appear to be limited to within the jet potential core.

Figure 18 shows the centerline variation of $\gamma$ inside the nozzle and illustrates the temperature dependence. The $40 \%$ temperature reduction through the nozzle results in a $2.5 \%$ increase in the ratio of specific heats. Much of this variation occurs downstream of the nozzle throat as the flow accelerates to Mach 2. Contours of $\gamma$ in the plume region are shown in figure 19. Within this region, $\gamma$ is a function of both temperature and the species mass fractions, since the exhaust gas mixes with the freestream air.

The centerline velocity decay shown in figure 20 reveals little difference in the length of the potential core regardless of the use of the various gas models or near-wall approaches. However, within the range $0 \leq x / D \leq 10$ one observes some minor variations in the velocity within the potential core region. As shown in figure 21, the perfect and frozen gas exhaust simulations show an increase in the velocity shortly after exiting the nozzle, while the simulations featuring the default perfect gas air model indicates a decrease near the same location. These differences are a further result of the expansion behavior within the nozzle and the pressure waves caused by a slight over- or underexpansion of the nozzle. Comparing with the available data, it appears that the use of the actual exhaust gas properties provides better agreement than simply using air. Differences between the perfect and frozen gas exhaust are somewhat less significant, and neither completely matches the data.

Velocity and turbulence profile results within the plume region are shown in figures 22 and 23. Some small differences within the first jet diameter are evident and are most likely related to the slightly different nozzle expansions produced by the gas models. The peak values of the turbulent kinetic energy are found to be equivalent. Therefore these small differences in solutions are not expected to impact any noise prediction results derived from them.

Thrust results for this supersonic nozzle are listed in Table 5 and exhibit similar trends in both the inviscid analysis and CFD. For the simulations modeled using the exhaust gas, the pressure thrust is positive indicating the flow is slightly underexpanded. With air as the working gas, the pressure thrust is negative indicating the flow is slightly overexpanded. These minor under- and overexpansions result in corresponding weak expansion and compression waves immediately downstream of the nozzle exit. The presence of such waves are corroborated by the observations of centerline velocity in figure 21. Overall, the use of different gas models was found to produce less than one quarter percent variation in the predicted gross thrust. However, the exhaust gas led to mass flow rates that are $3 \%$ less than that using air.

The use of wall functions had little observable effect on the mean flow quantities examined in the plume region, and the predicted mass flow rates were essentially the same as those obtained using wall integration. The near-wall region for this case was better resolved than for the convergent nozzle, with $y^{+} \approx 35$ and nearly twenty points within the boundary layer. The wall function model did predict somewhat larger displacement thicknesses of the boundary layer inside the nozzle compared to the wall integration results. This resulted in less effective area at the nozzle exit. The wall function solutions thus undergo less expansion than the wall integration cases, resulting in a slightly smaller momentum thrust and a larger pressure thrust. The net result is roughly $0.3 \%$ lower gross thrust when wall functions are used.

Table 6 compares the thrust coefficient results for the different gas models using the various approaches for computing $V_{\text {ideal }}$ described previously. For this nozzle, when the exhaust gas results are normalized by the nozzle ideal exit velocity of air, the thrust coefficients exceed one. Computing $V_{\text {ideal }}$ with a perfect gas assumption and a constant $\gamma$ representative of the gas mixture results in much better agreement of the gross thrust coefficient with the simulation results using perfect gas air. Unlike for the convergent nozzle case, this technique does not work as well for the frozen gas exhaust results. The remaining disparity between the perfect and frozen gas exhaust performance values are resolved when the frozen gas exhaust solution is normalized by the ideal exit velocity for a thermally perfect gas. 


\section{Discussion}

Based upon the results of the previous sections, the following general trends can be summarized. When the working fluid is changed from perfect gas air to either perfect or frozen gas exhaust, the nozzle mass flow rate is reduced. A greater percent reduction was found for the supersonic nozzle. The nozzle exit velocity, on the other hand, increases. If one merely uses $V_{\text {ideal }}$ for air to compute the gross thrust coefficient of an exhaust gas simulation, the values obtained may be overly optimistic. However, if the same gas model assumptions are used in computing $V_{\text {ideal }}$ as in the simulation, then comparable gross thrust coefficients can be obtained using any of the various gas modeling assumptions.

For higher speed applications such as hypersonic propulsion systems, which operate at even higher temperatures and nozzle pressure ratios, one would expect the proper accounting of $V_{\text {ideal }}$ to be of greater importance. Many such designs involve ramjet or scramjet combustion, which may not be complete before entering the nozzle. These configurations would require a more sophisticated modeling of the combustion physics than the frozen flow presented herein.

The findings of these studies can also be extrapolated to experimental results. When reporting performance data for hot supersonic nozzles, it is important to document the assumptions used in computing $V_{\text {ideal }}$. For air heated above a few hundred degrees Rankine, the ratio of specific heats may need to be adjusted to a value less than 1.4. Likewise, if the nozzle stream is heated by means of a combustor, then knowledge of the exhaust gas composition may be needed in order to make allowances for the thermodynamic effects of the additional chemical species.

\section{Conclusion}

In this study, the effect of the gas model assumption on nozzle exhaust simulations has been examined. Differences in the molecular composition of clean air and a representative exhaust gas mixture yield differences in their thermodynamic properties. These differences do not appear to have a significant effect on predictions for subsonic, low temperature flows. For hot supersonic nozzles, when both gases are assumed to be calorically perfect, these differences were found to result in a slight over- or underexpansion. The use of the frozen gas exhaust model produced more physically realistic results over the standard perfect gas air model. Perfect gas simulations of the exhaust gas mixture captured most, but not all, of the features of the frozen chemistry solution. The ability of the perfect gas exhaust simulations to capture the underexpansion of the nozzle demonstrates the importance of choosing the proper gas properties when using a perfect gas model. Estimation of values for quantities such as $R$ and $\gamma$ are possible if the gas mixture composition is known.

Some small differences between solutions were observed in the plume region of the supersonic nozzle. This was mostly due to the small over and underexpansions within the nozzle that result from differences in the thermodynamic properties of the gas models used. However, these differences are not significant enough to alter primary jet characteristics, such as core length or peak turbulence values, and are therefore unlikely to alter noise predictions derived from these solutions.

The gross thrust is relatively insensitive to the gas model used. When computing the thrust coefficient, however, one must be careful to normalize using the proper value for the nozzle ideal exit velocity. Normalizing exhaust gas solutions using an ideal velocity for perfect gas air resulted in an overestimation of the nozzle gross thrust coefficient. When the same gas model assumption are used to compute the ideal exit velocity as in the simulations, comparable thrust coefficients are obtained. These findings also have implications for the reporting of experimental thrust performance, especially when the exact composition of the exhaust gas mixture is unknown. In that case it is important to fully document the assumptions used in computing the ideal exit velocity, as ignoring the specifics of that choice can lead to overly optimistic performance results. 


\section{Appendix A: Calculation of the Ideal Nozzle Exit Velocity}

The ideal exit velocity is computed assuming isentropic flow through the nozzle. From the conservation of total enthalpy,

$$
h_{o}=h+\frac{1}{2} V^{2}
$$

the nozzle exit velocity can be expressed as

$$
V_{e}=\sqrt{2\left[h_{o}-h_{e}\right]}
$$

where $h_{o}$ is the stagnation enthalpy at the nozzle entrance and $h_{e}$ is the static enthalpy at the nozzle exit.

For a thermally perfect gas, the specific heats are functions of temperature and the enthalpy values are given by

$$
\begin{array}{ll}
h_{o}=h\left(T_{o}\right) & h(T)=\sum_{i=1, n s} Y_{i} h_{i}(T) \\
h_{e}=h\left(T_{e}\right) & h_{i}(T)=\int_{T_{\text {ref }}}^{T} C_{p_{i}} d T
\end{array}
$$

The function $h_{i}(T)$ is provided by means of look-up tables or curve-fit approximations to available experimental data. ${ }^{12}$ In order to relate $T_{e}$ to the nozzle exit pressure $P_{e}$, the first and second laws of thermodynamics are applied and the process is assumed to be isentropic.

$$
\Delta s=\int_{T_{o}}^{T_{e}} C_{p} \frac{d T}{T}-R \int_{P_{o}}^{P_{e}} \frac{d P}{P}=0
$$

A look-up function is also used for the quantity

$$
s_{i}(T)=\int_{T_{r e f}}^{T} C_{p_{i}} \frac{d T}{T}
$$

such that Eq. (14) can be written as an implicit relation for $T_{e}$. Since the flow expands completely $\left(P_{e}=P_{\infty}\right)$ the nozzle pressure ratio can be substituted.

$$
\begin{aligned}
\sum_{i=1, n s} Y_{i} s_{i}\left(T_{e}\right) & =\sum_{i=1, n s} Y_{i} s_{i}\left(T_{o}\right)-R \ln \left(\frac{P_{o}}{P_{e}}\right) \\
& =\sum_{i=1, n s} Y_{i} s_{i}\left(T_{o}\right)-R \ln (N P R)
\end{aligned}
$$

Once $T_{e}$ is determined, the ideal exit velocity is computed from Eqs. (11), (12), and (13).

For a calorically perfect gas, the specific heats are constant and the enthalpy values are given by

$$
\begin{aligned}
& h_{o}=C_{p} T_{o} \\
& h_{e}=C_{p} T_{e}
\end{aligned}
$$

Eq. (14) can be solved in closed form to determine $T_{e}$

$$
\frac{T_{e}}{T_{o}}=\left(\frac{P_{o}}{P_{e}}\right)^{(1-\gamma) / \gamma}=N P R^{(1-\gamma) / \gamma}
$$

and the ideal nozzle exit velocity can be expressed as

$$
V_{e}=\sqrt{\frac{2 \gamma}{\gamma-1} R T_{o}\left[1-N P R^{(1-\gamma) / \gamma}\right]}
$$




\section{References}

1.Khavaran, A. and Kenzakowski, D. C., "Noise Generation in Hot Jets," NASA CR-2007-214924, Jan. 2007, Presented as AIAA Paper 2007-3640.

2.Yoder, D. A., Georgiadis, N. J., and Wolter, J. D., "Quadrant Analysis of a Mixer-Ejector Nozzle for Supersonic Transport Applications," AIAA Journal of Propulsion and Power, Vol. 22, No. 1, Jan. 2007, pp. 250-253, See also NASA TM-2005-213602.

3.DeBonis, J., "RANS Analyses of Turbofan Nozzles with Wedge Deflectors for Noise Reduction," AIAA Paper 2008-0041, Jan. 2008.

4.Dippold, V., F. L. and Wiese, M., "Computational Analyses of Offset Stream Nozzles for Noise Reduction," AIAA Paper 2007-3589, May 2007.

5.Bridges, J. E. and Khavaran, A., "Assessment of Current Jet Noise Prediction Capabilities," AIAA Paper 2008-2933, May 2008.

6.Bridges, J. E. and Wernet, M. P., "Measurements of the Aeroacoustic Sound Source in Hot Jets," AIAA Paper 20033130, May 2003.

7.Seiner, J. M., Ponton, M. K., Jansen, B. J., and Lagan, N. T., "The Effects of Temperature on Supersonic Jet Noise Emission," AIAA Paper 92-02-046, May 1992.

8.Barber, T., Chiappetta, L., Debonis, J., Georgiadis, N., and Yoder, D., "Assessment of Parameters Influencing the Prediction of Shear-Layer Mixing," Journal of Propulsion and Power, Vol. 15, No. 1, Jan. 1999, pp. 45-53.

9.Georgiadis, N. J., Yoder, D. A., and Engblom, W. A., "Evaluation of Modified Two-Equation Turbulence Models for Jet Flow Predictions," AIAA Journal, Vol. 44, No. 12, 2006, pp. 3107-3114.

10.Dembowski, M. A. and Georgiadis, N. J., "An Evaluation of Parameters Influencing Jet Mixing Using the WIND Navier-Stokes Code," NASA TM-211727, Aug. 2002. 1992.

11.Menter, F. R., "Improved Two-Equation $k-\omega$ Turbulence Models for Aerodynamic Flows," NASA TM-103975, Oct.

12.McBride, B., Gordon, S., and Reno, M. A., "Thermodynamic Data for Fifty Reference Elements," NASA TP3287/REV1, Feb. 2001. 


\begin{tabular}{|l|cl|}
\hline Gas Model & $R\left(\mathrm{ft}^{2} / \mathrm{s}^{2} \mathrm{R}\right)$ & $\gamma$ \\
\hline Perfect Gas Air & 1716 & 1.400 \\
Perfect Gas Exhaust & 1745 & 1.373 \\
Frozen Gas Exhaust & 1745 & $1.373^{\dagger}$ \\
\hline
\end{tabular}

${ }^{\dagger} \gamma$ varies with temperature. Value shown is $\gamma\left(T_{0}\right)$.

Table 1. Gas model constants for convergent nozzle calculations $\left(\mathbf{N P R}=1.103, T_{0}=962{ }^{\circ} \mathbf{R}\right)$.

\begin{tabular}{|l|l|cccc|}
\hline \multirow{3}{*}{ Wall Model } & Gas Model & $\begin{array}{c}\text { Mass Flow } \\
\text { Rate } \\
\dot{m}(\mathrm{lbm} / \mathrm{s})\end{array}$ & $\begin{array}{c}\text { Momentum } \\
\text { Thrust } \\
F_{m}(\mathrm{lbf})\end{array}$ & $\begin{array}{c}\text { Pressure } \\
\text { Thrust } \\
F_{p}(\mathrm{lbf})\end{array}$ & $\begin{array}{c}\text { Gross } \\
\text { Thrust } \\
F_{g}(\mathrm{lbf})\end{array}$ \\
\hline 1D Inviscid & Perfect Gas Air & 0.508 & 8.916 & 0.000 & 8.916 \\
& Perfect Gas Exhaust & 0.503 & 8.910 & 0.000 & 8.910 \\
& Perfect Gas Air & 0.497 & 8.559 & 0.081 & 8.640 \\
& Perfect Gas Exhaust & 0.492 & 8.554 & 0.081 & 8.634 \\
& Frozen Gas Exhaust & 0.493 & 8.573 & 0.074 & 8.647 \\
& Perfect Gas Air & 0.493 & 8.440 & 0.111 & 8.551 \\
Wall Function & Perfect Gas Exhaust & 0.488 & 8.436 & 0.111 & 8.547 \\
(revised) & Frozen Gas Exhaust & 0.489 & 8.468 & 0.092 & 8.560 \\
& Perfect Gas Air & 0.495 & 8.510 & 0.100 & 8.610 \\
& Perfect Gas Exhaust & 0.491 & 8.507 & 0.099 & 8.605 \\
& Frozen Gas Exhaust & 0.491 & 8.520 & 0.092 & 8.611 \\
\hline
\end{tabular}

Table 2. Convergent nozzle thrust results $\left(\mathrm{NPR}=1.103, T_{0}=962{ }^{\circ} \mathrm{R}\right)$.

\begin{tabular}{|l|l|c|c|c|}
\hline \multicolumn{2}{|c|}{ Simulation Models } & \multicolumn{3}{|c|}{ Thrust Coefficient, $C_{f g}$, using Different $V_{\text {ideal }}$ Gas Models } \\
\hline \multirow{4}{*}{ Wall Model } & Gas Model & $\begin{array}{c}\text { Perfect Gas Air } \\
\left(R_{\text {air }}, \gamma_{\text {air }}\right) \\
V_{\text {ideal }}=565 \mathrm{ft} / \mathrm{s}\end{array}$ & $\begin{array}{c}\text { Perfect Gas Exhaust } \\
(R, \gamma) \\
V_{\text {ideal }}=570 \mathrm{ft} / \mathrm{s}\end{array}$ & $\begin{array}{c}\text { Frozen Gas Exhaust } \\
\left(R, \gamma_{(T)}\right) \\
V_{\text {ideal }}=569 \mathrm{ft} / \mathrm{s}\end{array}$ \\
\hline Integration & Perfect Gas Air & 0.991 & 0.991 & \\
& Perfect Gas Exhaust & 1.000 & 0.991 & 0.992 \\
& Frozen Gas Exhaust & 0.999 & 0.989 & \\
Wall Function & Perfect Gas Air & 0.989 & 0.988 & 0.990 \\
(revised) & Perfect Gas Exhaust & 0.997 & 0.997 & \\
& Frozen Gas Exhaust & 0.990 & 0.990 & 0.991 \\
\hline
\end{tabular}

Table 3. Convergent nozzle thrust coefficient results $\left(\mathrm{NPR}=1.103, T_{0}=962{ }^{\circ} \mathrm{R}\right)$. 


\begin{tabular}{|l|cl|}
\hline Gas Model & $R\left(\mathrm{ft}^{2} / \mathrm{s}^{2 \circ} \mathrm{R}\right)$ & $\gamma$ \\
\hline Perfect Gas Air & 1716 & 1.400 \\
Perfect Gas Exhaust & 1745 & 1.305 \\
Frozen Gas Exhaust & 1745 & $1.305^{\dagger}$ \\
\hline
\end{tabular}

${ }^{\dagger} \gamma$ varies with temperature. Value shown is $\gamma\left(T_{0}\right)$.

Table 4. Gas model constants for convergent-divergent nozzle calculations $\left(\mathrm{NPR}=7.82, T_{0}=2460{ }^{\circ} \mathbf{R}\right)$.

\begin{tabular}{|l|l|cccc|}
\hline \multirow{3}{*}{ Wall Model } & Gas Model & $\begin{array}{c}\text { Mass Flow } \\
\text { Rate } \\
\dot{m}(\mathrm{lbm})\end{array}$ & $\begin{array}{c}\text { Momentum } \\
\text { Thrust } \\
F_{m}(\mathrm{lbf})\end{array}$ & $\begin{array}{c}\text { Pressure } \\
\text { Thrust } \\
F_{p}(\mathrm{lbf})\end{array}$ & $\begin{array}{c}\text { Gross } \\
\text { Thrust } \\
F_{g}(\mathrm{lbf})\end{array}$ \\
\hline \multirow{5}{*}{ Wntegration Inviscid } & Perfect Gas Air & 7.14 & 815.3 & -10.8 & 804.5 \\
& Perfect Gas Exhaust & 6.91 & 800.0 & 4.6 & 804.6 \\
& Perfect Gas Air & 7.09 & 793.4 & -3.7 & 789.7 \\
& Perfect Gas Exhaust & 6.86 & 778.6 & 11.1 & 789.7 \\
& Frozen Gas Exhaust & 6.87 & 781.2 & 7.4 & 788.6 \\
& Perfect Gas Air & 7.08 & 790.0 & -2.6 & 787.5 \\
& Perfect Gas Exhaust & 6.86 & 775.3 & 12.1 & 787.5 \\
& Frozen Gas Exhaust & 6.86 & 777.8 & 8.5 & 786.4 \\
\hline
\end{tabular}

Table 5. Convergent-divergent nozzle thrust results $\left(\mathrm{NPR}=7.82, T_{0}=2460{ }^{\circ} \mathrm{R}\right)$.

\begin{tabular}{|c|c|c|c|c|}
\hline \multicolumn{2}{|c|}{ Simulation Models } & \multicolumn{3}{|c|}{ Thrust Coefficient, $C_{f g}$, using Different $V_{\text {ideal }}$ Gas Models } \\
\hline Wall Model & Gas Model & $\begin{array}{c}\text { Perfect Gas Air } \\
\quad\left(R_{a i r}, \gamma_{a i r}\right) \\
V_{\text {ideal }}=3624 \mathrm{ft} / \mathrm{s}\end{array}$ & $\begin{array}{c}\text { Perfect Gas Exhaust } \\
\qquad(R, \gamma) \\
V_{\text {ideal }}=3744 \mathrm{ft} / \mathrm{s}\end{array}$ & $\begin{array}{c}\text { Frozen Gas Exhaust } \\
\qquad\left(R, \gamma_{(T)}\right) \\
V_{\text {ideal }}=3735 \mathrm{ft} / \mathrm{s}\end{array}$ \\
\hline Wall Function & $\begin{array}{l}\text { Perfect Gas Air } \\
\text { Perfect Gas Exhaust } \\
\text { Frozen Gas Exhaust } \\
\text { Perfect Gas Air } \\
\text { Perfect Gas Exhaust } \\
\text { Frozen Gas Exhaust }\end{array}$ & $\begin{array}{l}0.989 \\
1.021 \\
1.019 \\
0.987 \\
1.020 \\
1.017\end{array}$ & $\begin{array}{l}0.989 \\
0.986 \\
0.987 \\
0.985\end{array}$ & 0.989 \\
\hline
\end{tabular}

Table 6. Convergent-divergent nozzle thrust coefficient results $\left(N P R=7.82, T_{0}=2460{ }^{\circ} \mathbf{R}\right)$. 


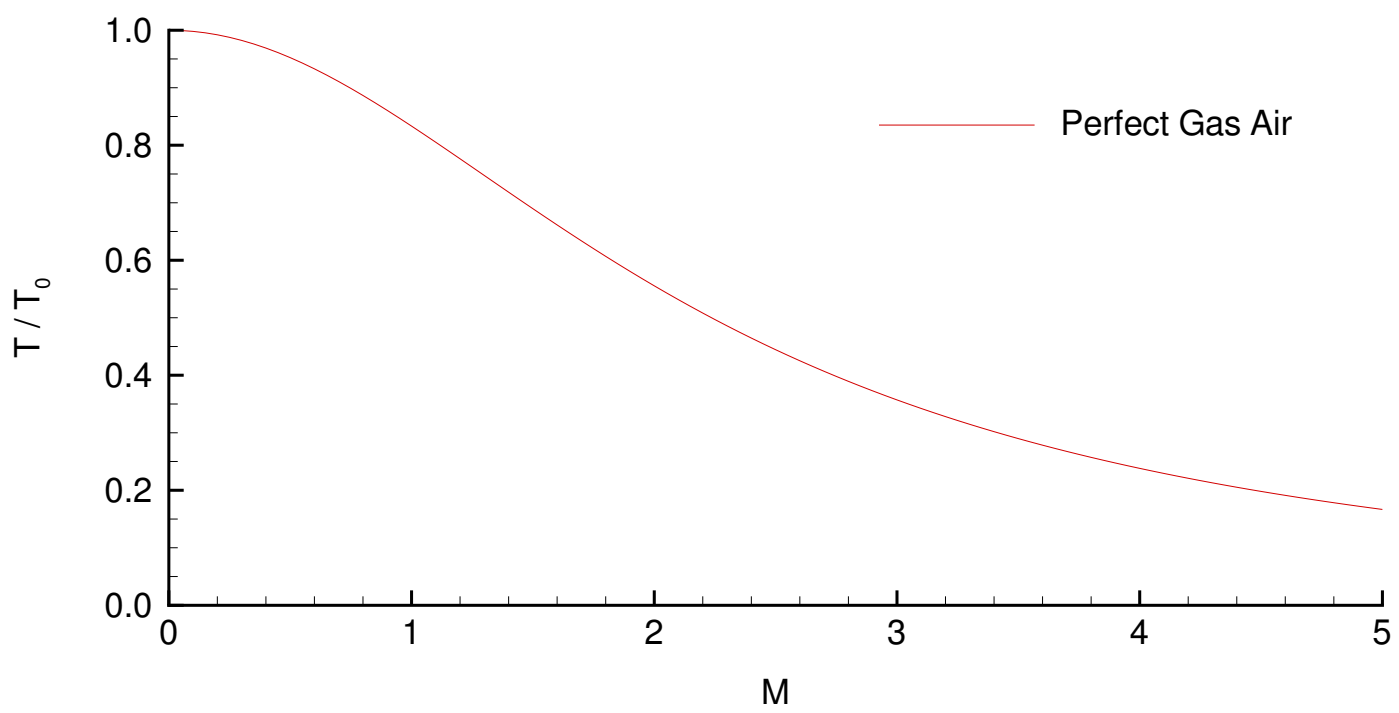

Figure 1. Isentropic relation between temperature and Mach number.

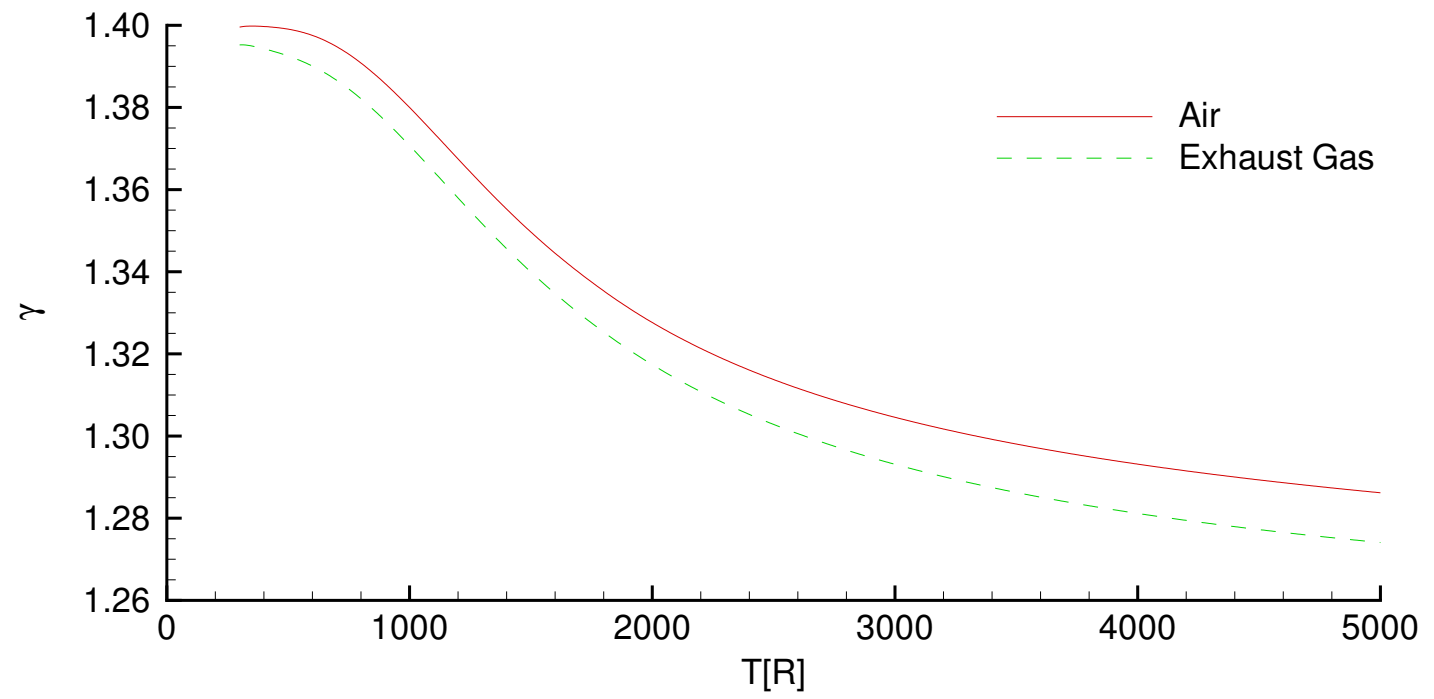

Figure 2. Dependence of specific heat ratio on temperature. 


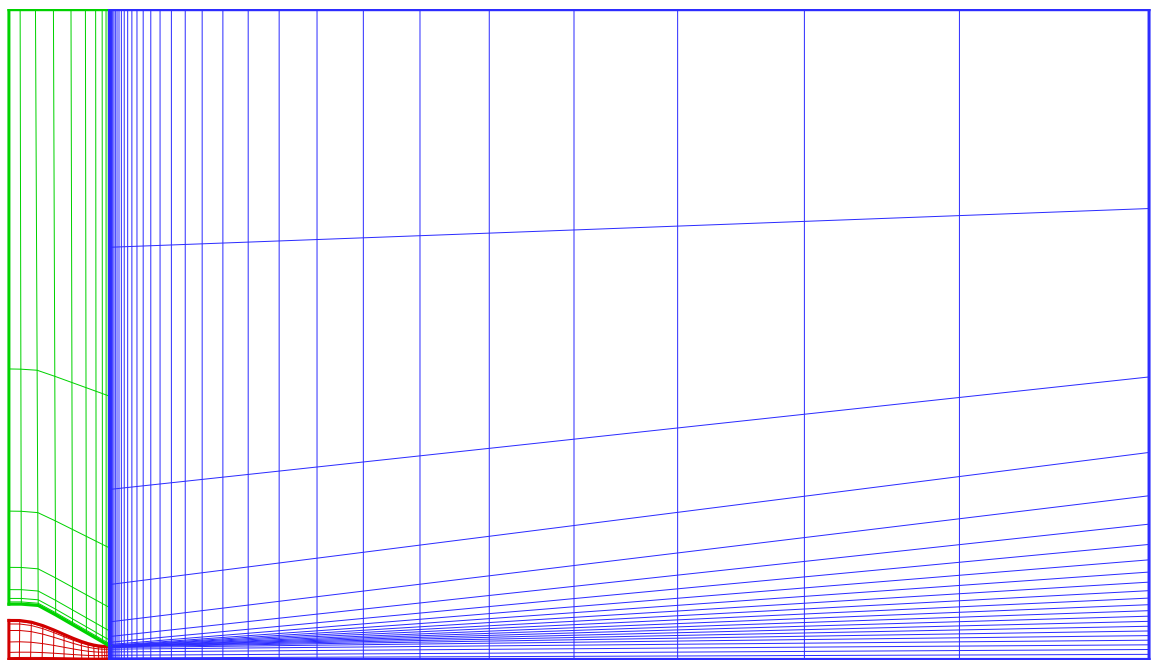

Figure 3. Mesh for convergent nozzle geometry (every 8th grid point shown).

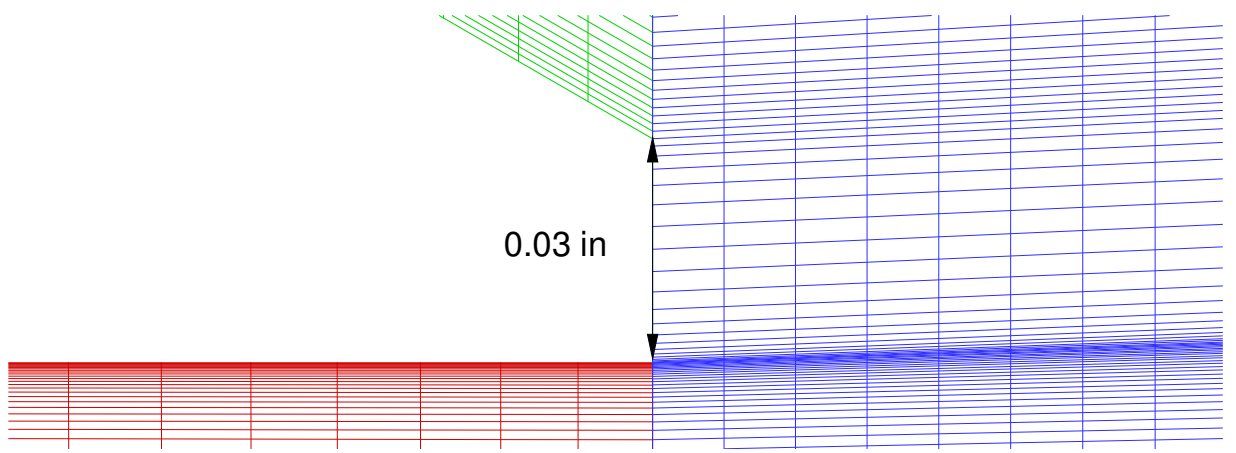

Figure 4. Grid spacing at lip for convergent nozzle wall integration cases.

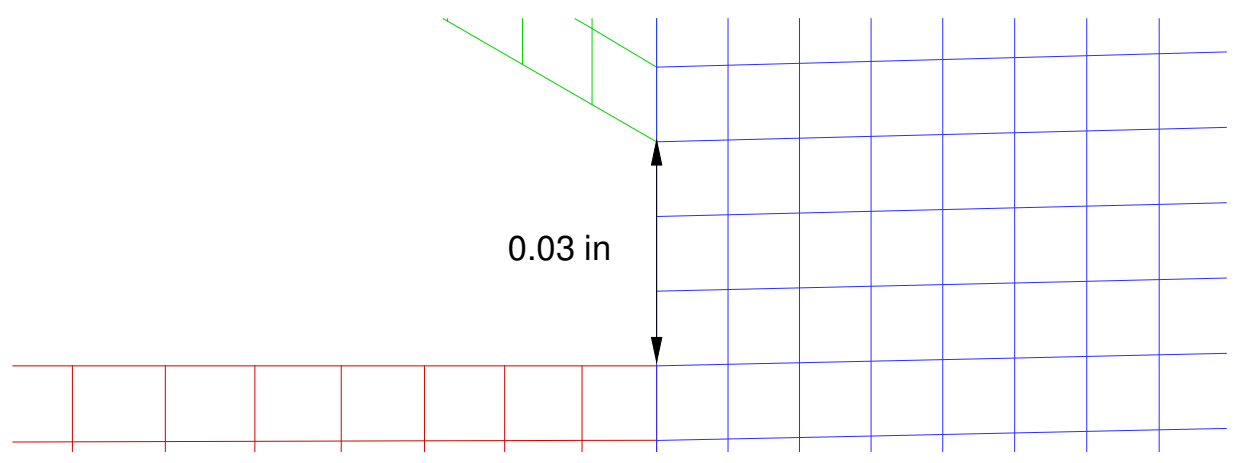

Figure 5. Grid spacing at lip for convergent nozzle wall function cases. 


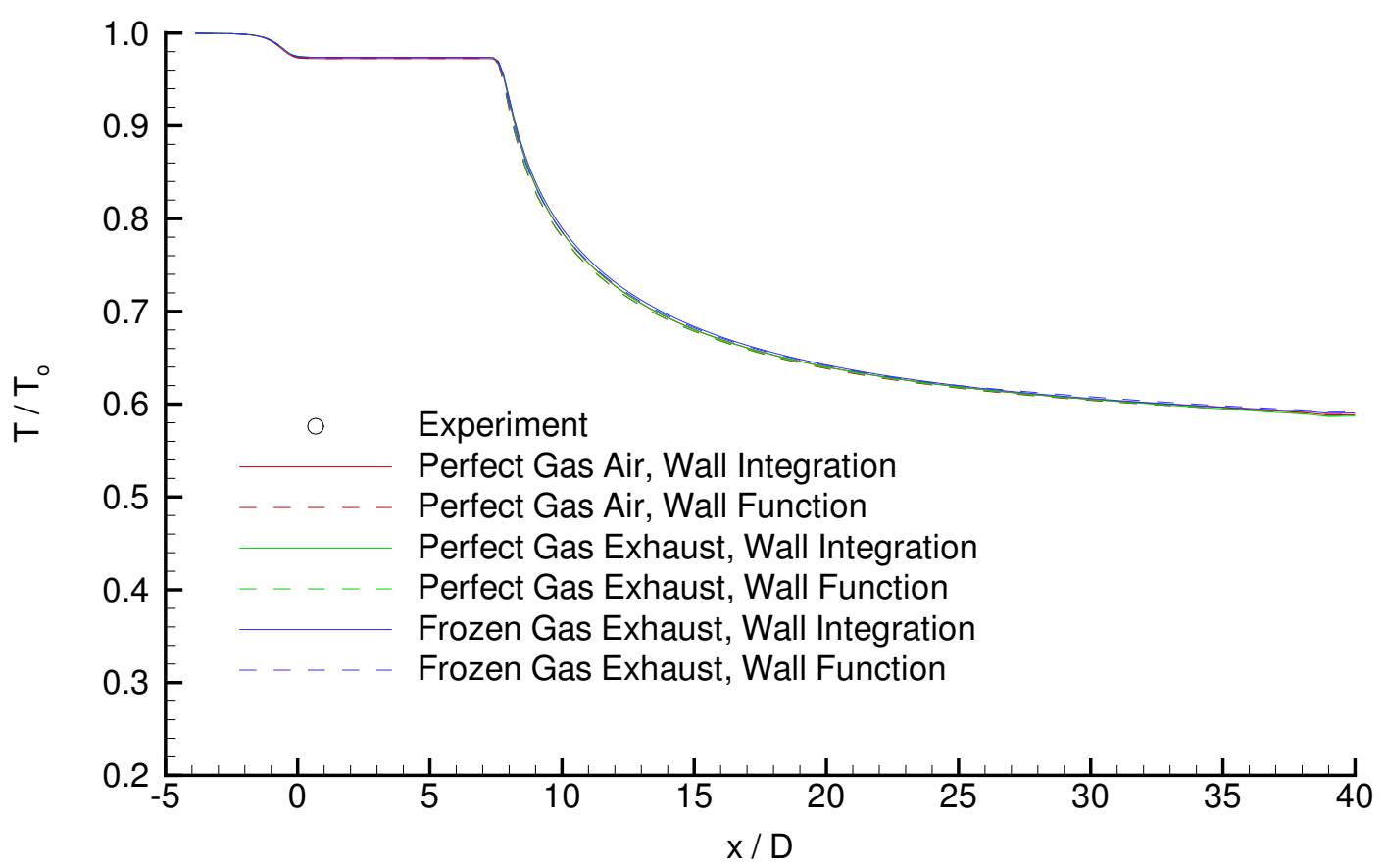

Figure 6. Centerline static temperature results for convergent nozzle.

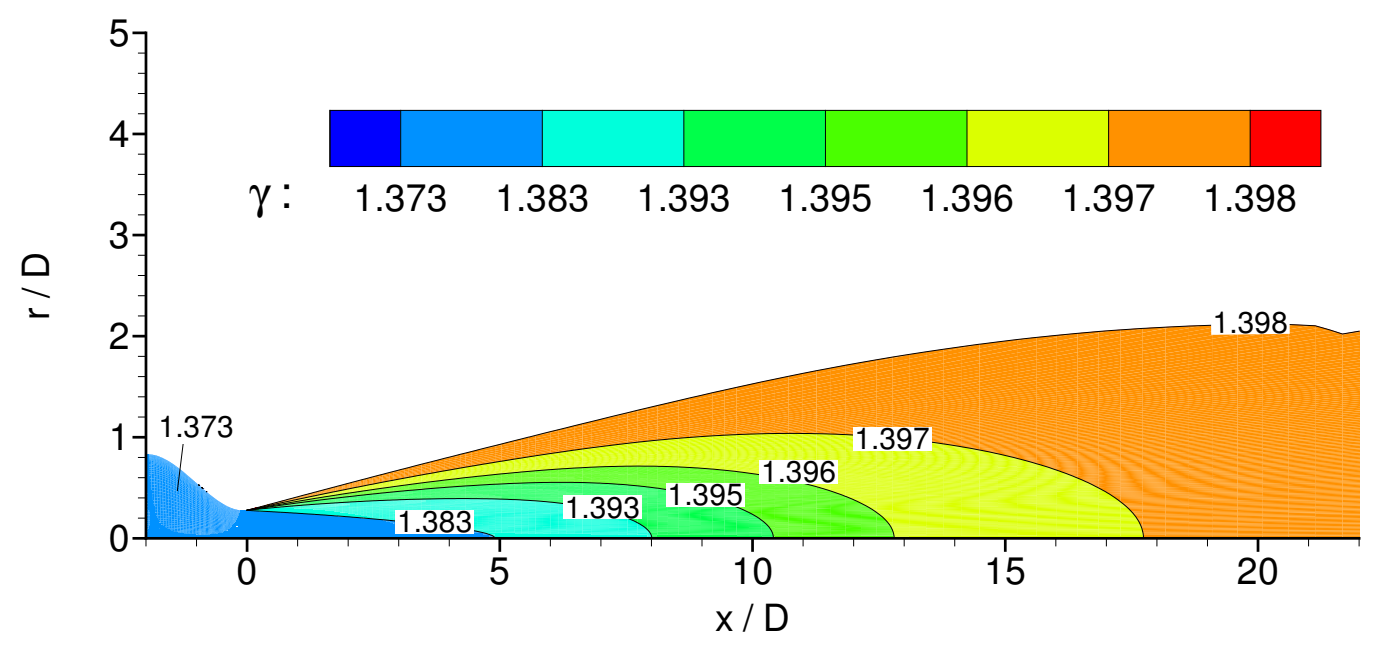

Figure 7. Convergent nozzle contours of specific heat ratio for subsonic nozzle. 


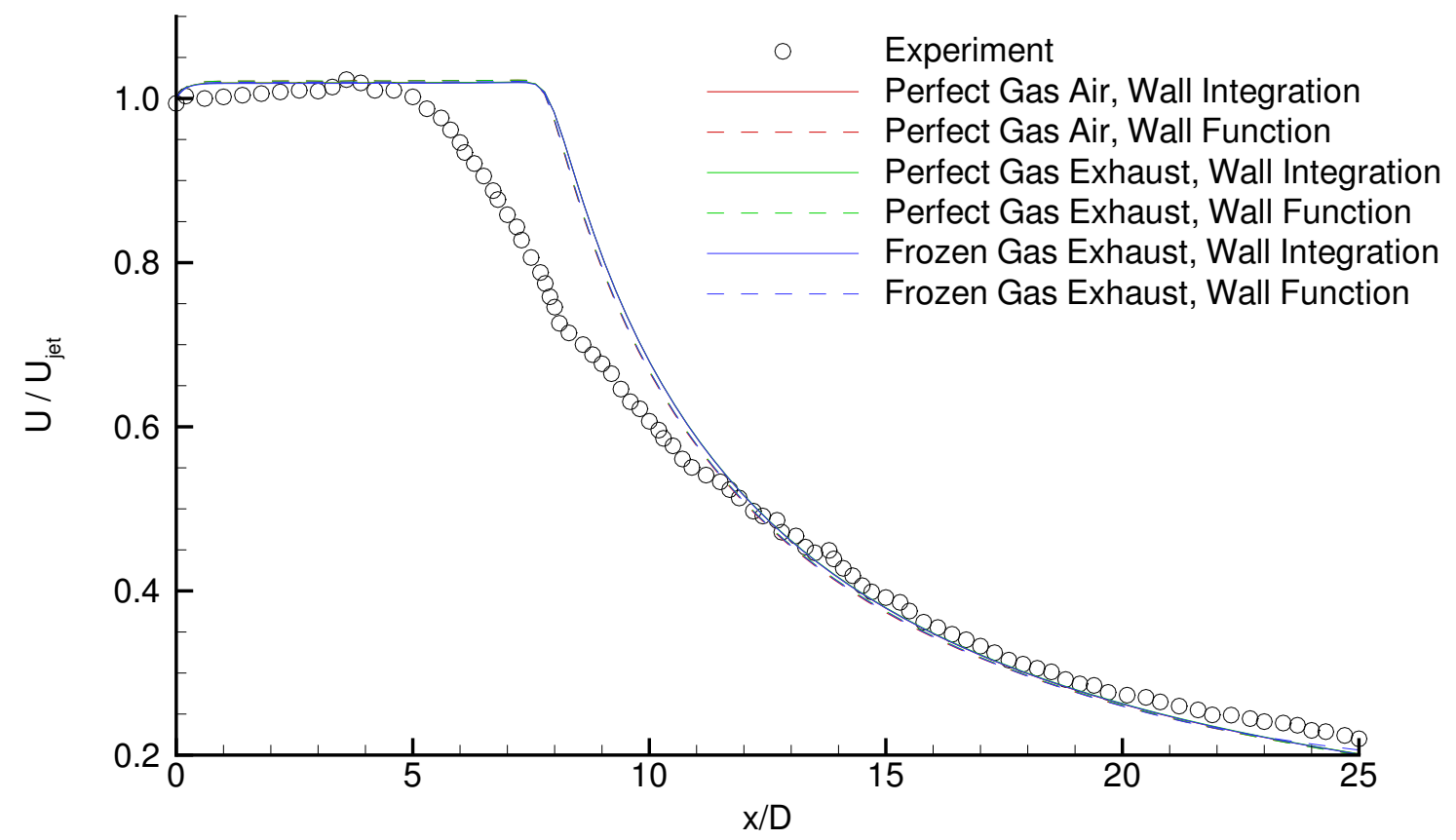

Figure 8. Centerline velocity results for convergent nozzle.

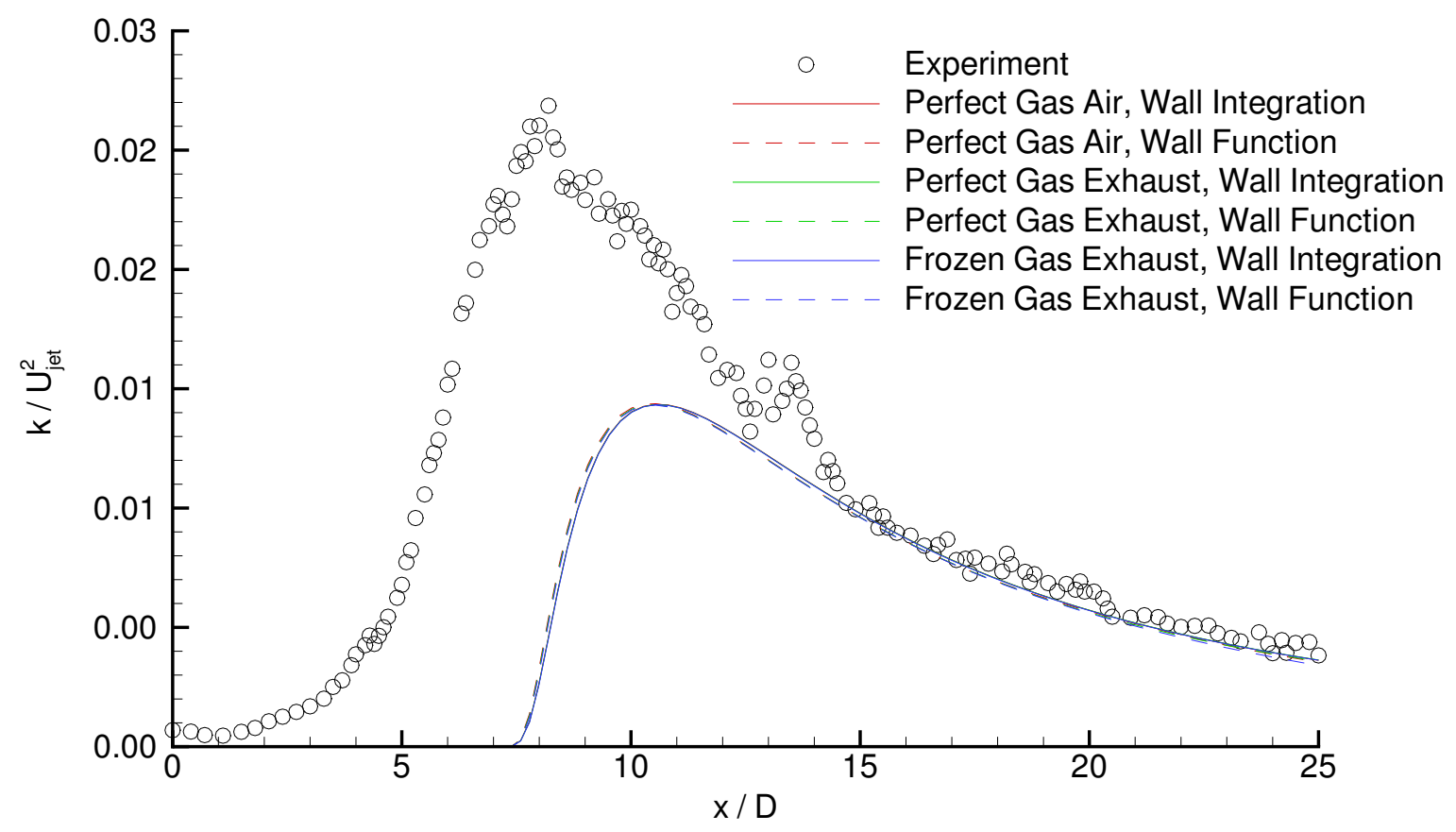

Figure 9. Centerline turbulent kinetic energy results for convergent nozzle. 


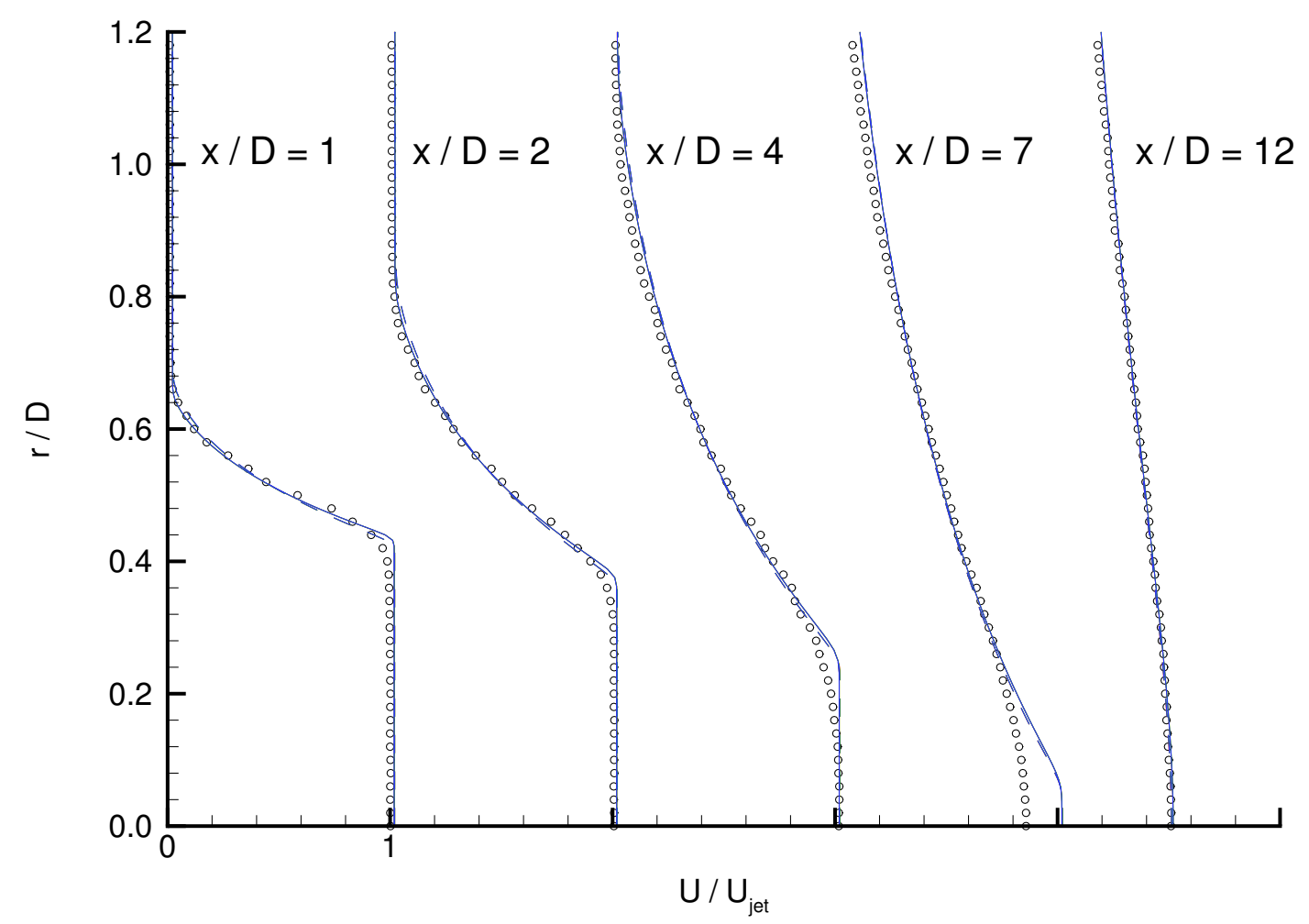

Figure 10. Velocity profile results for convergent nozzle (See figure 9 for legend).

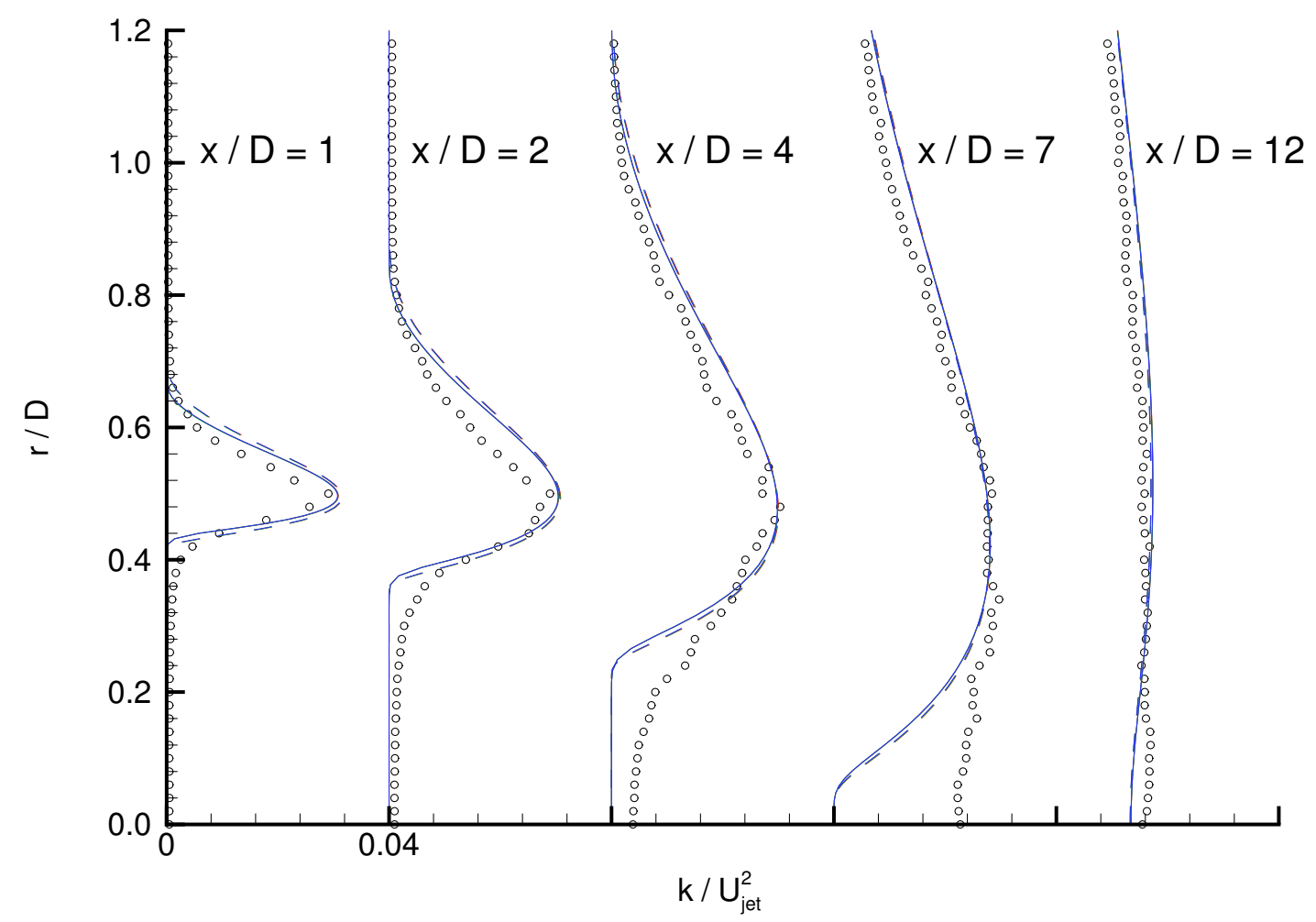

Figure 11. Turbulent kinetic energy profile results for convergent nozzle (See figure 9 for legend). 


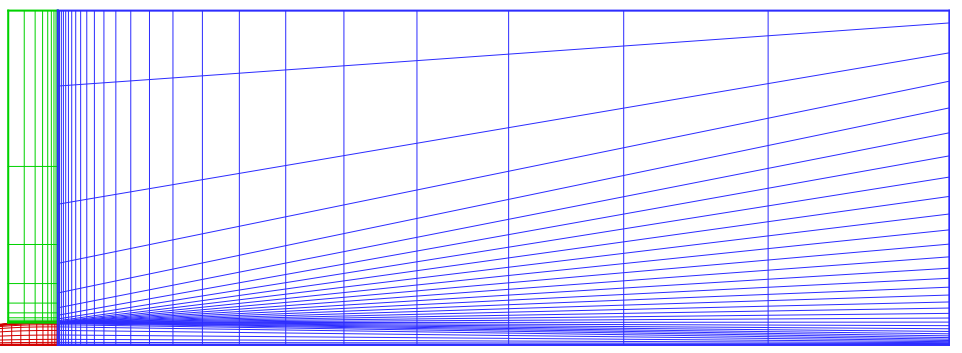

Figure 12. Mesh for convergent-divergent nozzle (every 5 th grid point shown).

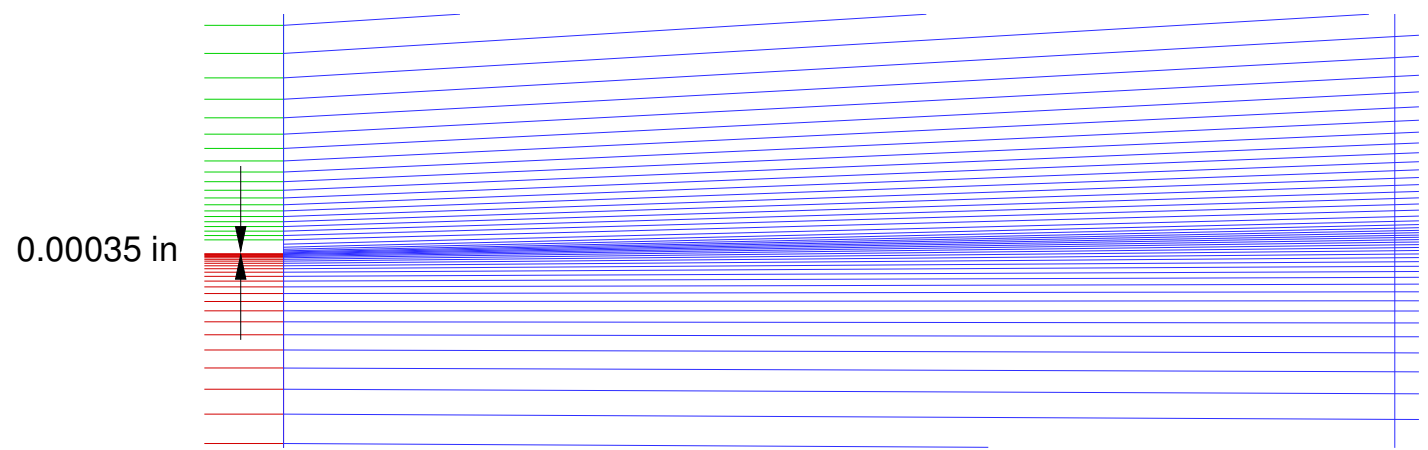

Figure 13. Grid spacing at lip for convergent-divergent nozzle wall integration cases.

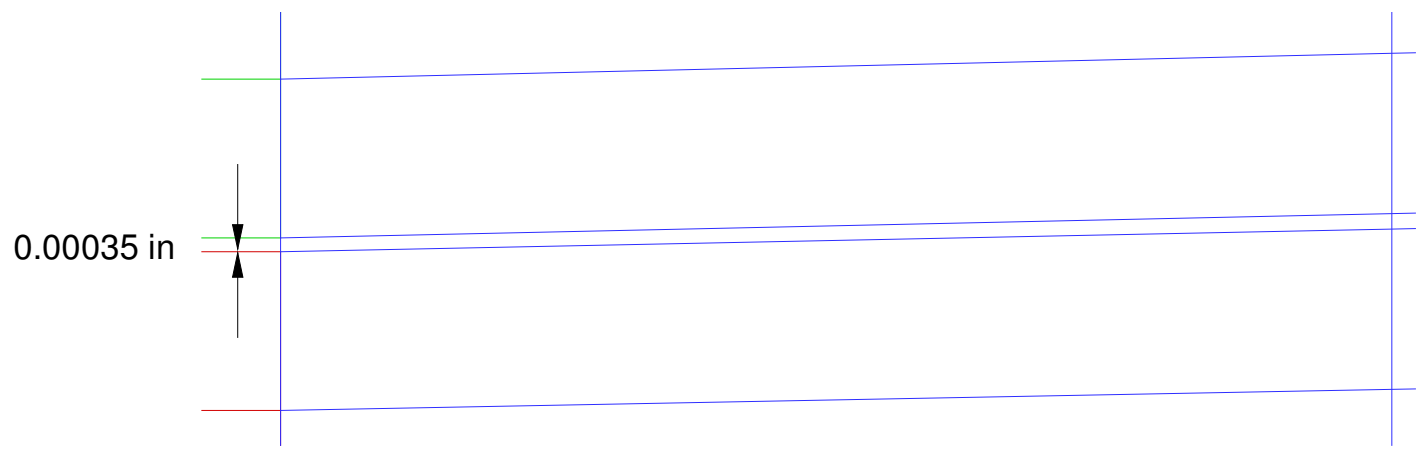

Figure 14. Grid spacing at lip for convergent-divergent nozzle wall function cases. 


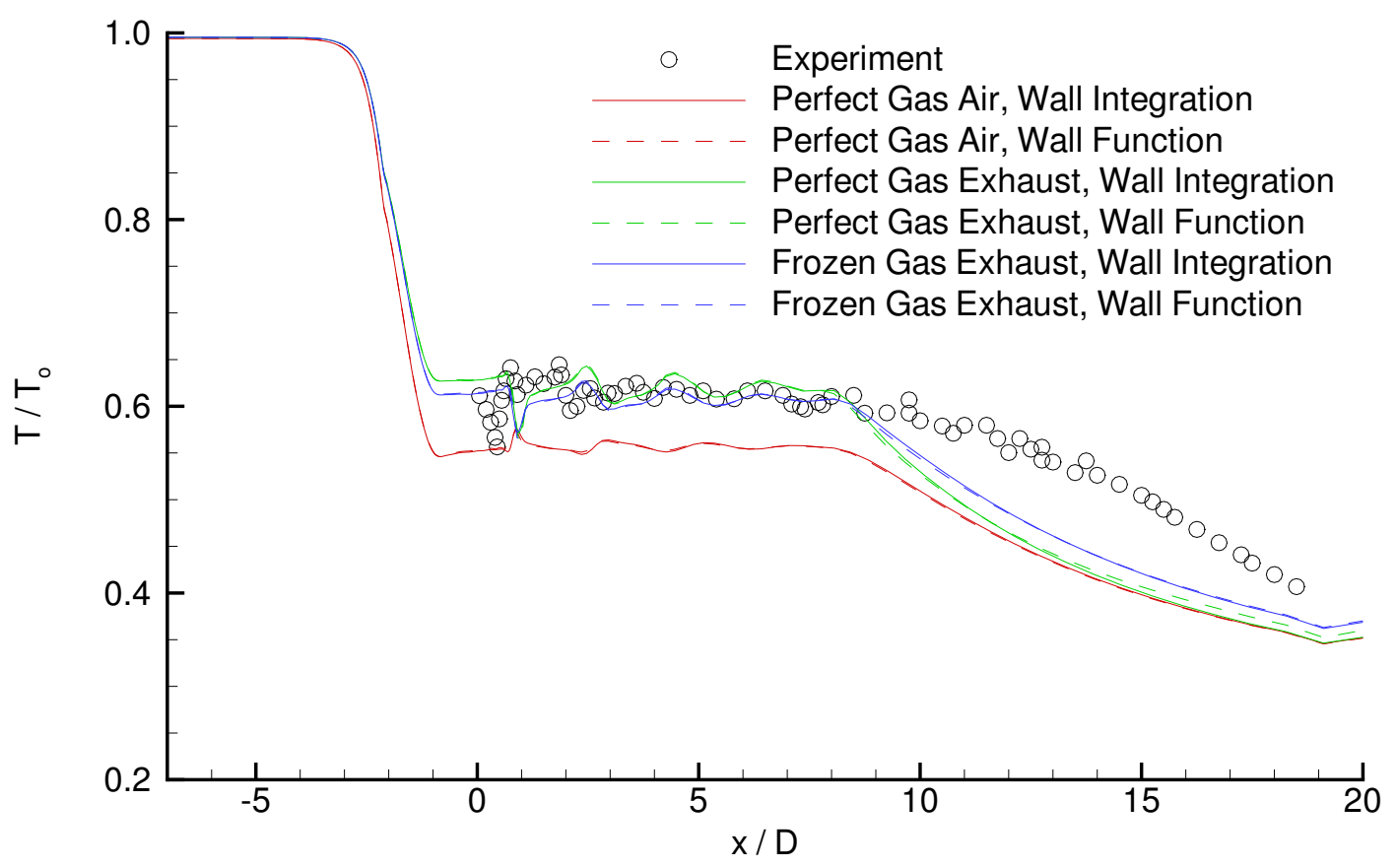

Figure 15. Convergent-divergent nozzle centerline static temperature decay.
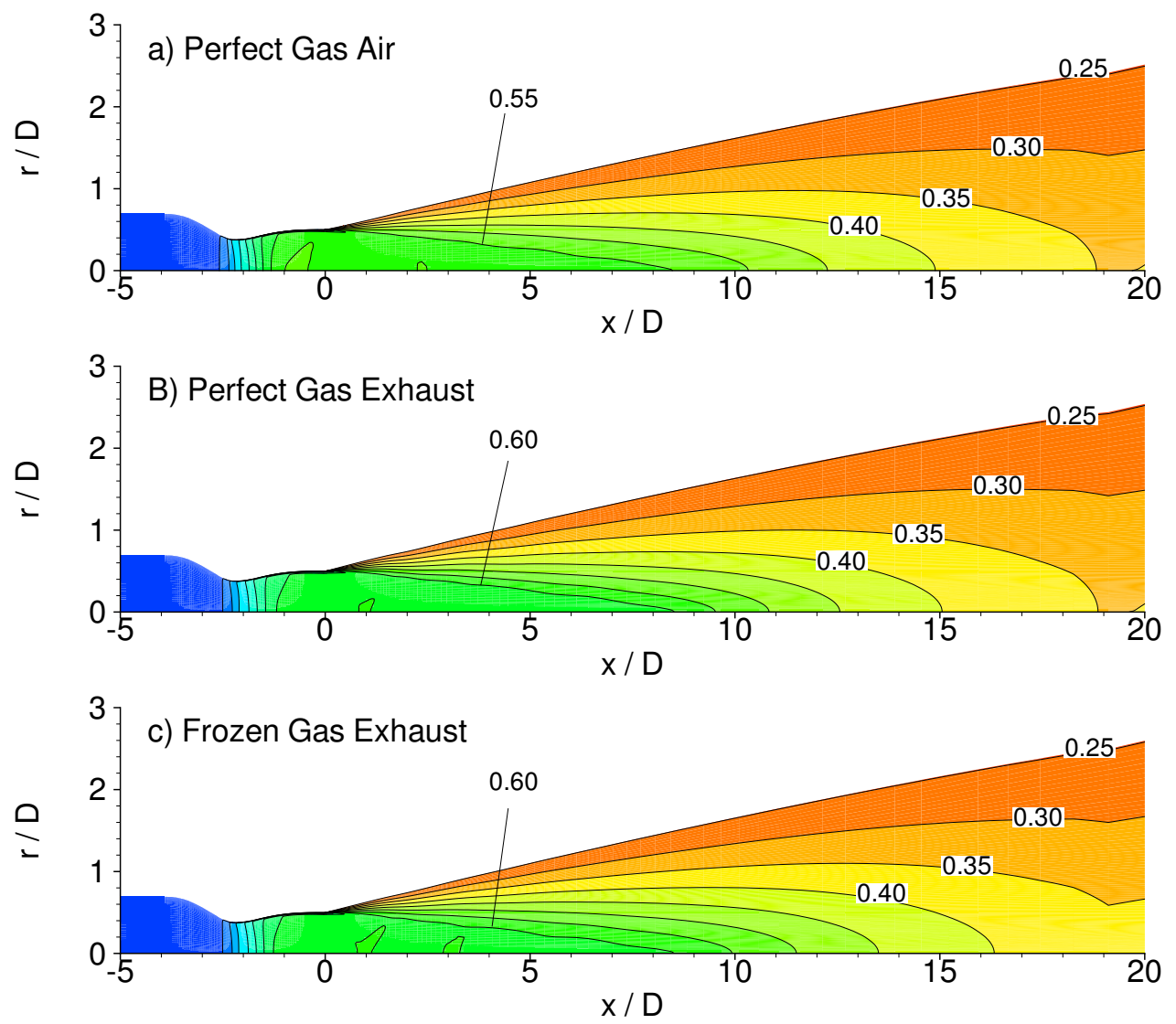

Figure 16. Convergent-divergent nozzle static temperature contours. 

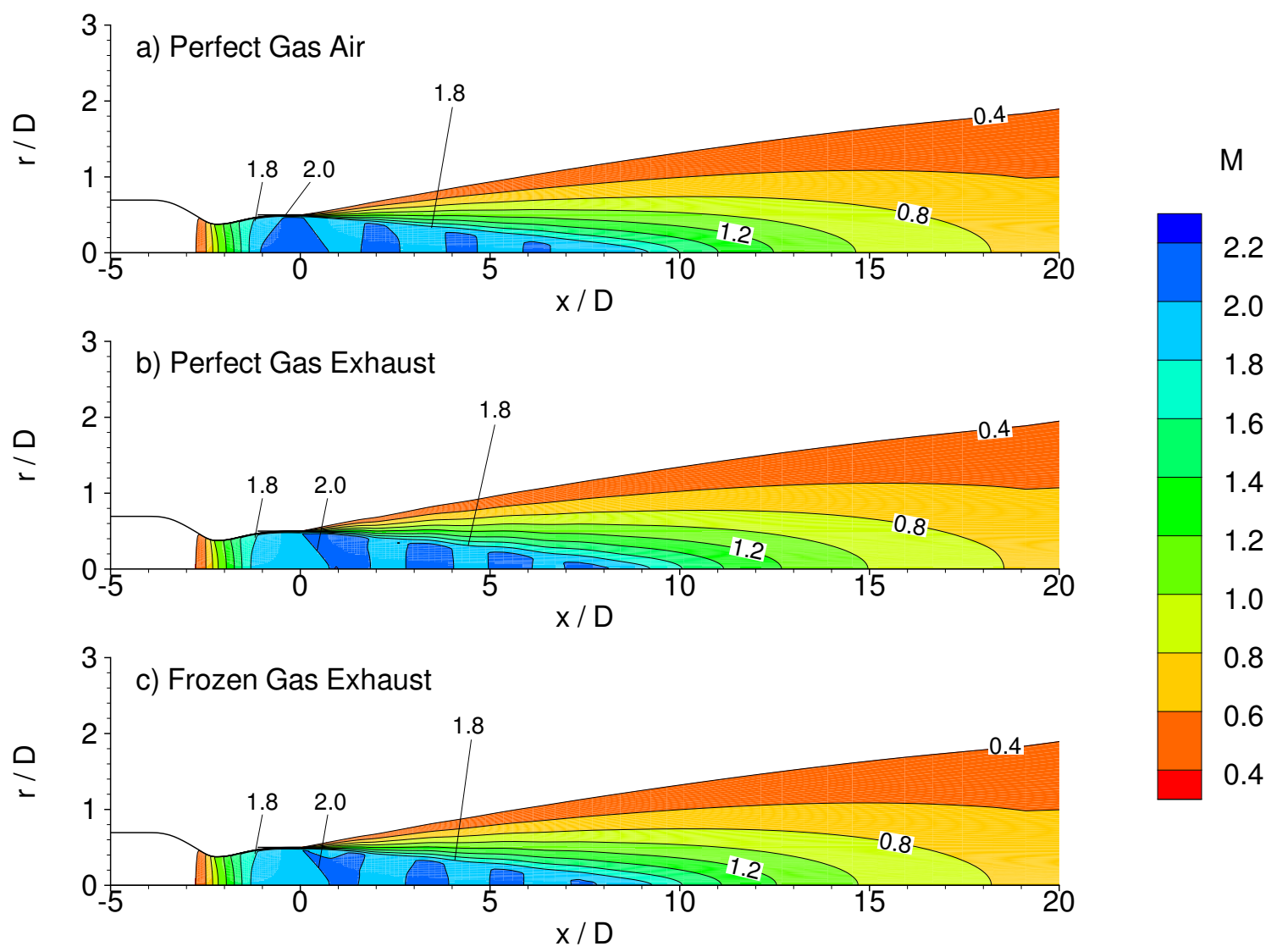

Figure 17. Convergent-divergent nozzle Mach number contours. 

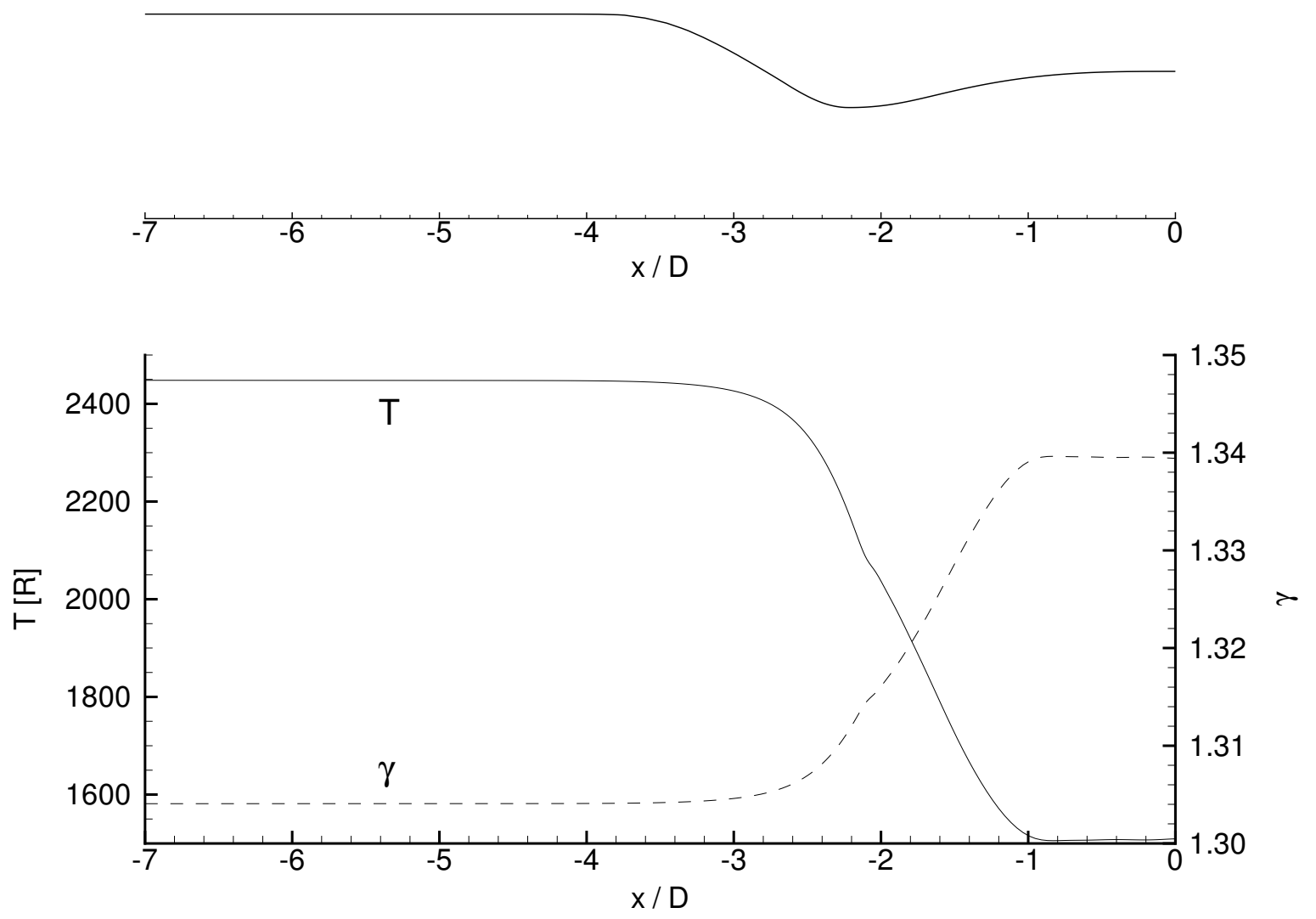

Figure 18. Convergent-divergent nozzle centerline variation of static temperature and specific heat ratio.

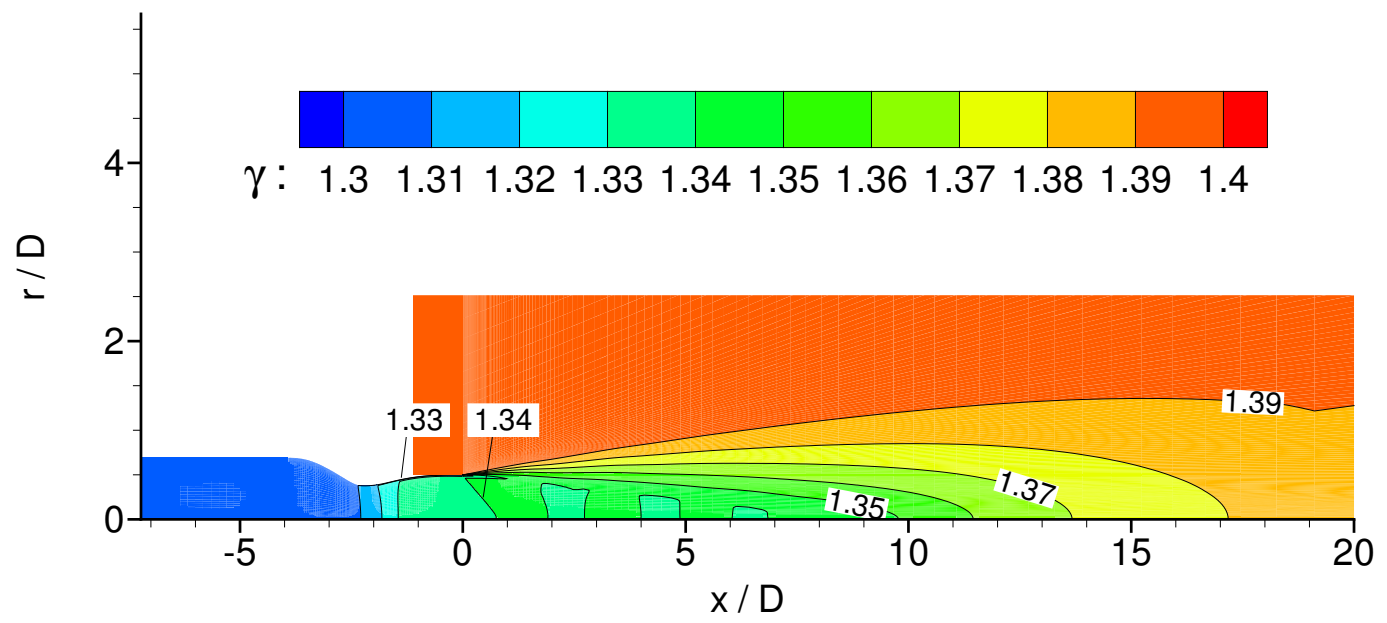

Figure 19. Convergent-divergent nozzle contours of specific heat ratio. 


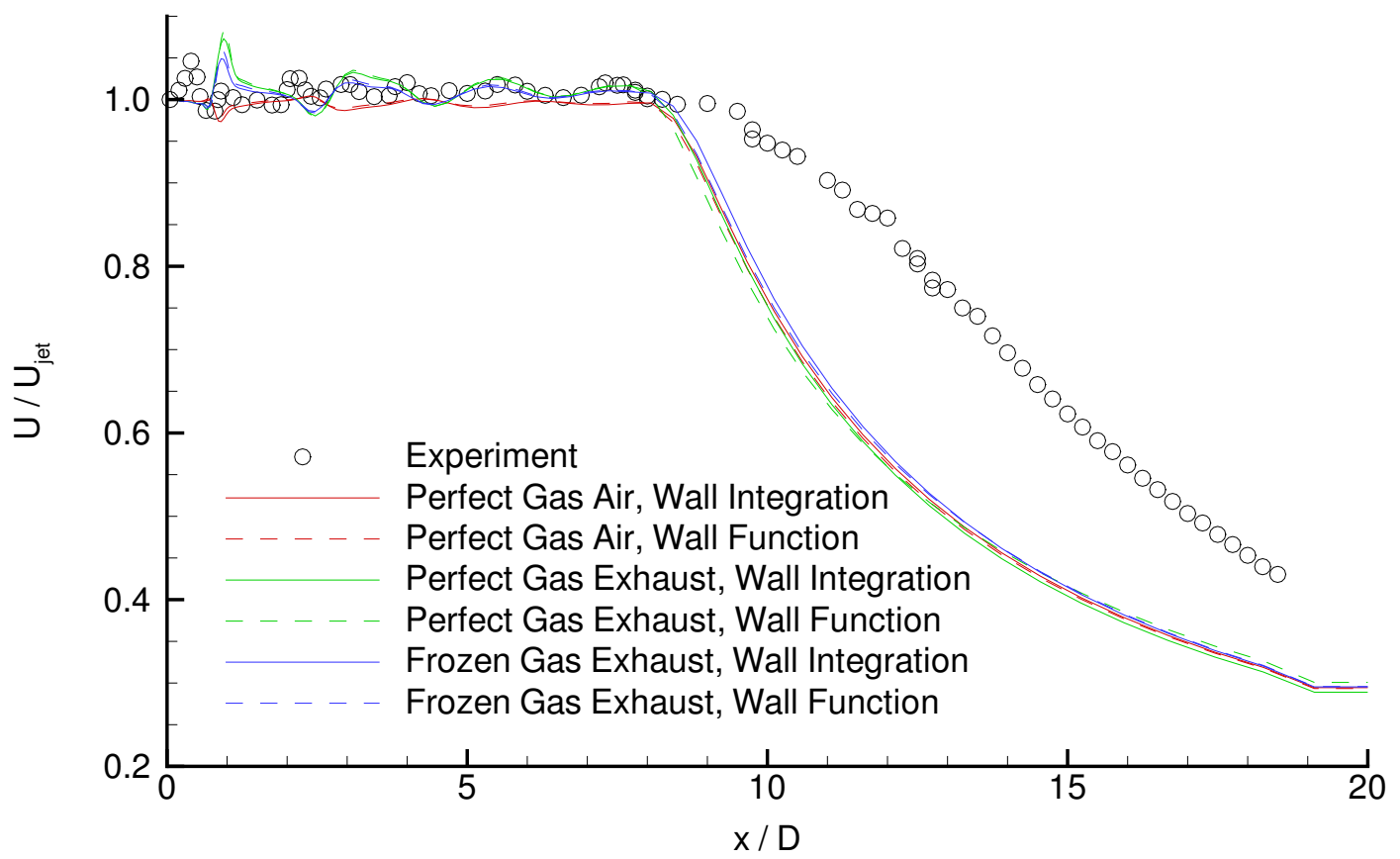

Figure 20. Convergent-divergent nozzle centerline velocity decay.

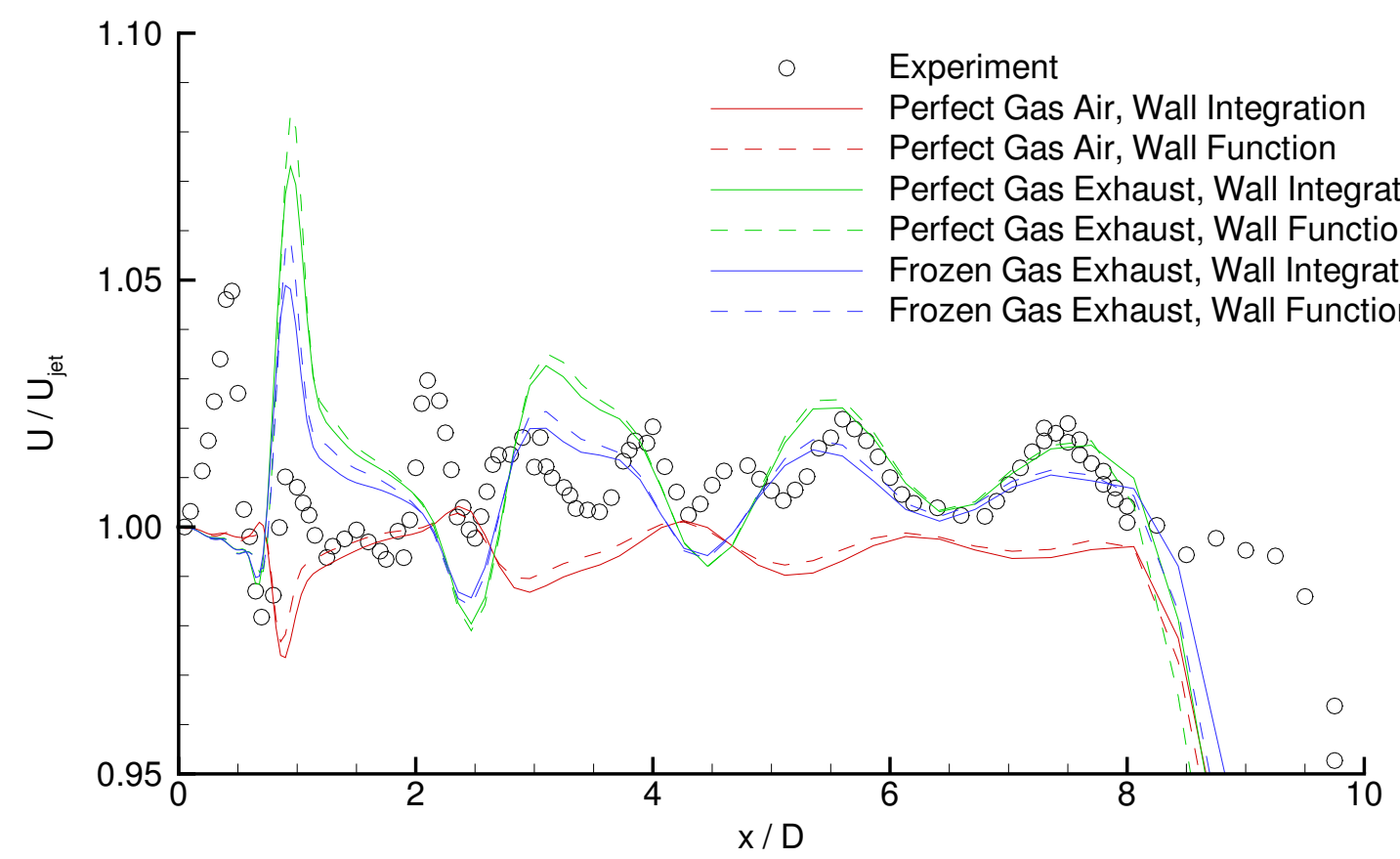

Figure 21. Detailed plot of convergent-divergent nozzle centerline velocity within the potential core region. 


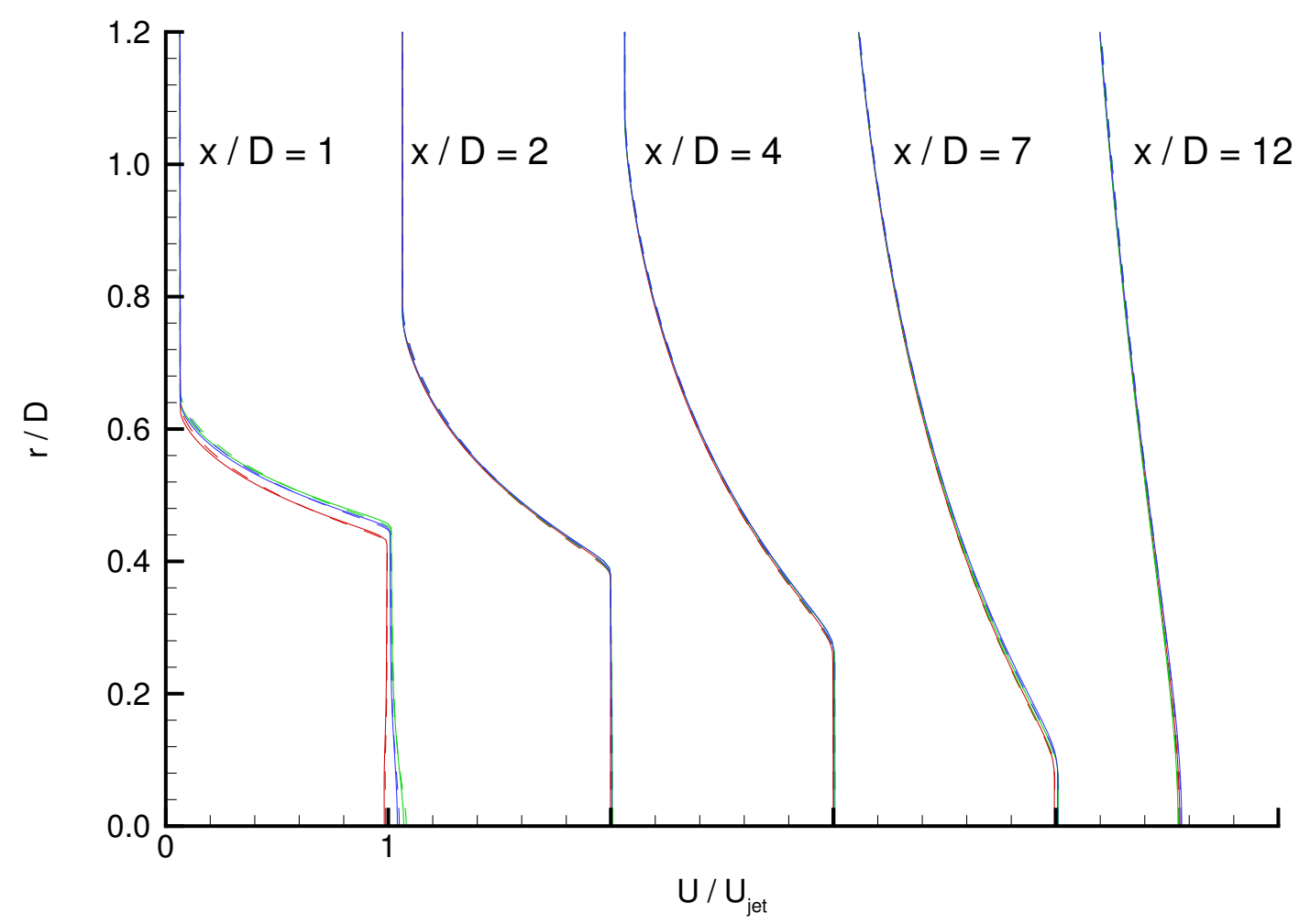

Figure 22. Jet velocity profiles for convergent-divergent nozzle (See figure 21 for legend).

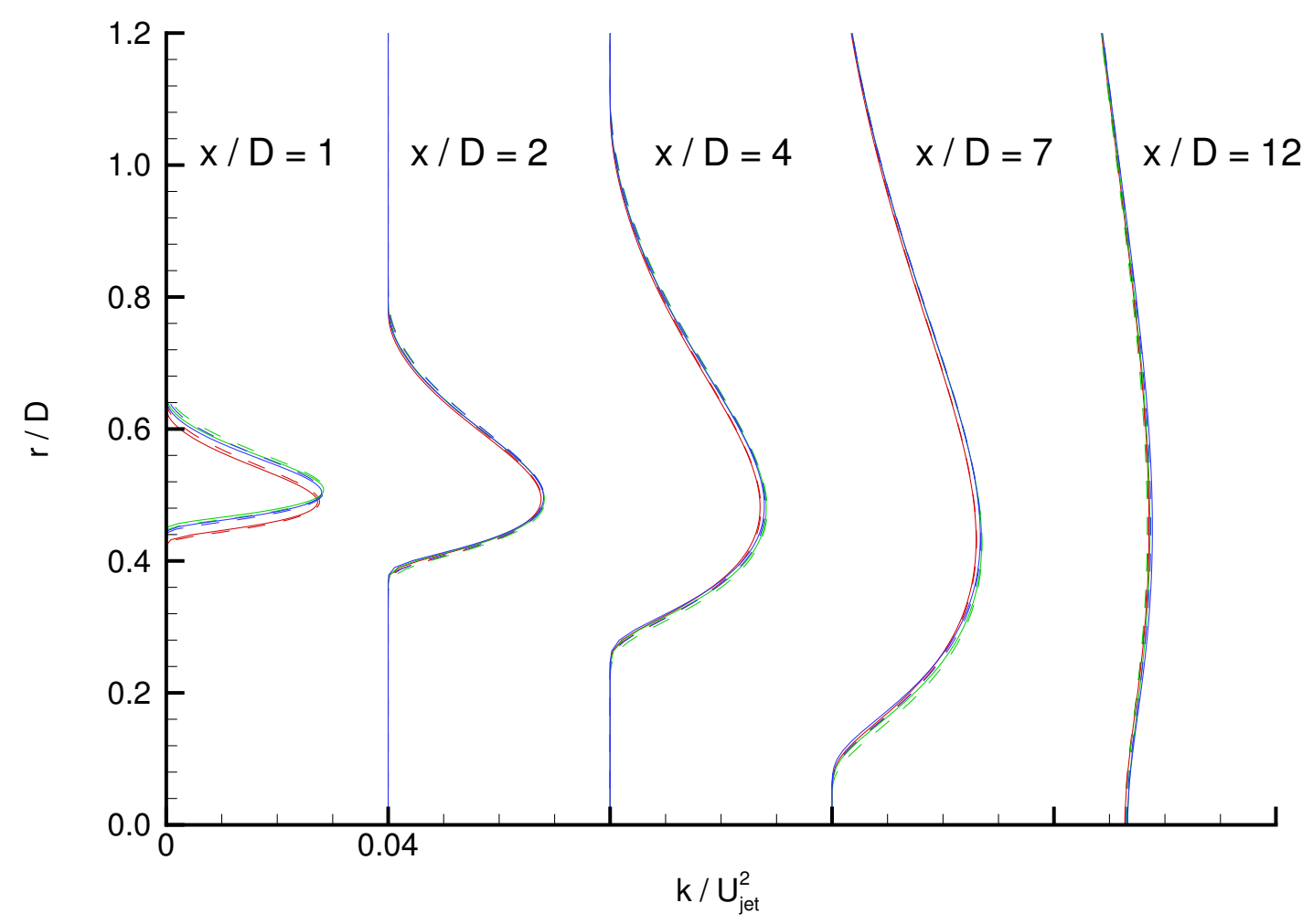

Figure 23. Turbulent kinetic energy profiles for convergent-divergent nozzle (See figure 21 for legend). 


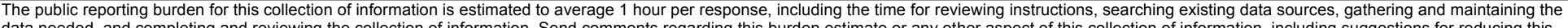

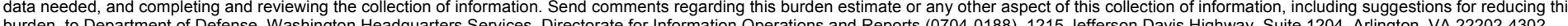

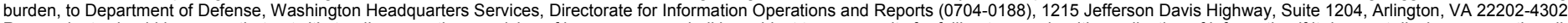

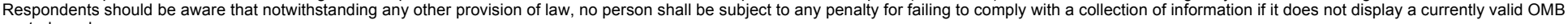
control number.

PLEASE DO NOT RETURN YOUR FORM TO THE ABOVE ADDRESS.
1. REPORT DATE (DD-MM-YYYY)
2. REPORT TYPE
3. DATES COVERED (From - To)
01-03-2009
Technical Memorandum

\section{TITLE AND SUBTITLE}

Frozen Chemistry Effects on Nozzle Performance Simulations

5a. CONTRACT NUMBER

5b. GRANT NUMBER

5c. PROGRAM ELEMENT NUMBER

6. AUTHOR(S)

Yoder, Dennis, A.; Georgiadis, Nicholas, J.; O'Gara, Michael, R.

5d. PROJECT NUMBER

5e. TASK NUMBER

5f. WORK UNIT NUMBER

WBS 659877.02.03.0654.01

7. PERFORMING ORGANIZATION NAME(S) AND ADDRESS(ES)

National Aeronautics and Space Administration

John H. Glenn Research Center at Lewis Field

Cleveland, Ohio 44135-3191

9. SPONSORING/MONITORING AGENCY NAME(S) AND ADDRESS(ES)

National Aeronautics and Space Administration

Washington, DC 20546-0001

\section{PERFORMING ORGANIZATION}

REPORT NUMBER

E-16672

\section{DISTRIBUTION/AVAILABILITY STATEMENT}

Unclassified-Unlimited

Subject Category: 07

Available electronically at http://gltrs.grc.nasa.gov

This publication is available from the NASA Center for AeroSpace Information, 301-621-0390

\section{SUPPLEMENTARY NOTES}

\section{ABSTRACT}

Simulations of exhaust nozzle flows are typically conducted assuming the gas is calorically perfect, and typically modeled as air. However the gas inside a real nozzle is generally composed of combustion products whose thermodynamic properties may differ. In this study, the effect of gas model assumption on exhaust nozzle simulations is examined. The three methods considered model the nozzle exhaust gas as calorically perfect air, a calorically perfect exhaust gas mixture, and a frozen exhaust gas mixture. In the latter case the individual nonreacting species are tracked and modeled as a gas which is only thermally perfect. Performance parameters such as mass flow rate, gross thrust, and thrust coefficient are compared as are mean flow and turbulence profiles in the jet plume region. Nozzles which operate at low temperatures or have low subsonic exit Mach numbers experience relatively minor temperature variations inside the nozzle, and may be modeled as a calorically perfect gas. In those which operate at the opposite extreme conditions, variations in the thermodynamic properties can lead to different expansion behavior within the nozzle. Modeling these cases as a perfect exhaust gas flow rather than air captures much of the flow features of the frozen chemistry simulations. Use of the exhaust gas reduces the nozzle mass flow rate, but has little effect on the gross thrust. When reporting nozzle thrust coefficient results, however, it is important to use the appropriate gas model assumptions to compute the ideal exit velocity. Otherwise the values obtained may be an overly optimistic estimate of nozzle performance.

\section{SUBJECT TERMS}

Exhaust gases; Exhaust nozzles; Nozzle thrust coefficients; Performance prediction

\begin{tabular}{|c|c|c|c|c|}
\hline \multicolumn{3}{|c|}{ 16. SECURITY CLASSIFICATION OF: } & \multirow{2}{*}{$\begin{array}{l}\text { 17. LIMITATION OF } \\
\text { ABSTRACT }\end{array}$} & \multirow{2}{*}{$\begin{array}{l}\text { 18. NUMBER } \\
\text { OF } \\
\text { PAGES } \\
29\end{array}$} \\
\hline $\begin{array}{l}\text { a. REPORT } \\
U\end{array}$ & $\begin{array}{l}\text { b. ABSTRACT } \\
U\end{array}$ & $\begin{array}{l}\text { c. THIS } \\
\text { PAGE } \\
\text { U }\end{array}$ & & \\
\hline
\end{tabular}

19a. NAME OF RESPONSIBLE PERSON STI Help Desk (email:help@sti.nasa.gov) 19b. TELEPHONE NUMBER (include area code) $301-621-0390$ 

